\title{
Recycling Endosomes Undergo Rapid Closure of a Fusion Pore on Exocytosis in Neuronal Dendrites
}

\author{
Damien Jullié, ${ }^{1,2}$ Daniel Choquet, ${ }^{1,2}$ and ${ }^{\circledR}$ David Perrais ${ }^{1,2}$ \\ ${ }^{1}$ University of Bordeaux and ${ }^{2}$ National Center of Scientific Research, Interdisciplinary Institute for Neuroscience, Coeducational Research Unit 5297, \\ F-33000 Bordeaux, France
}

Exocytosis of recycling endosomes (REs) represents the last step of receptor and membrane recycling, a fundamental process involved in many aspects of cell physiology. In neurons, it is involved in the control of cell polarity and synaptic plasticity and is locally and tightly regulated. However, its molecular mechanisms are still poorly understood. We have imaged single exocytosis events of REs in rat hippocampal neurons in culture transfected with three types of receptors tagged with the pH-sensitive GFP mutant superecliptic phluorin. We found that exocytosis events are grouped into two categories: (1) short burst events in which receptors diffuse into the plasma membrane in a few seconds; and (2) long display events in which receptors remain visible and clustered after exocytosis for many seconds. Display events are much rarer in non-neuronal cells, such as fibroblasts and astrocytes. Using two-color imaging and fast extracellular solution changes, we show that display events correspond to the rapid opening and closing of a fusion pore (or "kiss-andrun") with a median opening time of $2.6 \mathrm{~s}$, which restricts the diffusion of multiple receptor types and bound cargo. Moreover, the RE marker Rab11 remains enriched after display exocytosis events and controls the mode of RE exocytosis. Finally, a given RE can undergo multiple rounds of display exocytosis. The last step of recycling can thus be controlled in neurons for the selective delivery of receptors at the cell surface.

Key words: AMPA receptor; astrocyte; beta-adrenergic receptor; kiss-and-run; Rab11; transferrin receptor

\section{Introduction}

The endosomal system in neuronal dendrites is a major player in the establishment and maintenance of neuronal morphology and polarity, the expression of synaptic plasticity, and other forms of signaling (Hirling, 2009; Kennedy and Ehlers, 2011; Yap and Winckler, 2012). Specifically, the transport and exocytosis of recycling endosomes (REs) into dendritic spines is stimulated by protocols known to induce synaptic long-term potentiation (LTP), and interfering with the RE-specific Rab11a or its effector Rab11FIP2 abrogates LTP (Park et al., 2004, 2006; Brown et al., 2007; Wang et al., 2008). However, the conditions of RE exocytosis are still essentially unknown. Intriguingly, studies aimed at recording single exocytosis events from RE-containing recycled receptors tagged with the GFP mutant superecliptic phluorin (SEP), glutamate AMPA-type receptors (Yudowski et al., 2007; Lin et al., 2009; Makino and Malinow, 2009; Araki et al., 2010; Kennedy et al., 2010; Patterson et al., 2010), or receptors to neu-

\footnotetext{
Received Feb. 26, 2014; revised July 1, 2014; accepted July 8, 2014.

Author contributions: D.J. and D.P. designed the research; D.J. and D.P. performed the research; D.J. and D.P. analyzed the data; D.J., D.C., and D.P. wrote the paper.

This work was supported by the National Center of Scientific Research (Exploratory and Interface programs), the National Research Agency (D.P.), and the Aquitaine Regional Council. We thank Axel Athané, Christelle Breillat, Camille Genuer, Natacha Retailleau, and Emeline Verdier for help with molecular biology and neuronal culture and Sébastien Marais, Magali Mondin, and Christel Poujol (Bordeaux Imaging Center) for help with spinning-disk confocal microscopy. We also thank Morgane Rosendale and Olivier Thoumine for critically reading the manuscript. The authors declare no competing financial interests.

Correspondence should be addressed to David Perrais at the above address. E-mail: david.perrais@u-bordeaux.fr. DOI:10.1523/JNEUROSCI.0799-14.2014

Copyright $\odot 2014$ the authors $\quad 0270-6474 / 14 / 3411106-13 \$ 15.00 / 0$
}

romodulators (Yudowski et al., 2006) have uncovered two types of exocytosis events: (1) in one type, called transient or burst, receptors quickly diffuse into the plasma membrane after vesicle fusion; and (2) in the other type, called persistent or display, receptors remain visible and clustered at the site of exocytosis. It has been proposed that both types of exocytosis deliver receptors at the plasma membrane, but that for display events, receptors would not freely diffuse in the plasma membrane (Yudowski et al., 2007; Yu et al., 2010). Therefore, the site of exocytosis will condition receptor activation by extracellular ligands (Makino and Malinow, 2009). Moreover, the molecular mechanisms for such retentions are still unknown, and it is even unclear whether and how long these receptors remain accessible to extracellular ligands. To investigate the mechanisms of RE exocytosis in neurons, we have recorded single exocytosis events using the transferrin receptor (TfR), a general marker of REs, as well as other recycled receptors, the $\beta 2$ adrenergic receptor ( $\beta 2 \mathrm{AR})$ and the AMPA receptor subunit GluA1 fused to SEP. Using a combination of live-cell imaging approaches, fast extracellular solution changes, and two-color imaging, we have found that display events signal rapid opening and closing of a fusion pore of REs.

\section{Materials and Methods}

\section{Plasmid constructs}

TfR-SEP, $\beta 2$ AR-SEP, dynamin2-mCherry, and Rab5-mCherry plasmids were kindly provided by C. Merrifield (Laboratory of Enzymology and Structural Biochemistry, Gif-sur-Yvette, France) and Rabl1a-mCherry by J. Salamero (Curie Institute, Paris, France). Other Rab-mCherry plasmids were constructed as follows: Rab protein cDNAs were amplified by PCR 
(for Rab4a and Rab8, IMAGE rat clones, ImaGenes, Berlin, Germany; for Rab11 S25N, Rab35, and mutants, kind gifts from A. Echard, Pasteur Institute, Paris, France; and for Rab11 Q70L, kind gift from D. Bryant, University of California, San Francisco, San Francisco, CA) with the following primers: Rab4 forward, gcgcAAGCTTcgatggcgcagaccgccatgtcc; Rab4 reverse, gcgcGGATCCctagcagccacactcctgtgc; Rab8 forward, gcgcAAGCTTcgatggcgaagacctacgattacc; Rab8 reverse, gcgcGAATTCtcacaggagactgcaccgg; Rab11 forward, gAAGCTTgatgggcacccgcgacgacg; Rab11 reverse, GGATCCttatatgttctgacagcactgcacc; Rab35 forward, gAAGCTTcgatggccegggactacgaccacc; and Rab35 reverse, GGATCC ttagcagcagcg.

The DNA amplification products were then subcloned into pmCherry-C1 (Clontech) using HinDIII and EcoRI for Rab4 and HinDIII and BamHI for Rab8, Rab11, and Rab35 (restriction sites in upper case). pHtomato (pHto; kind gift from Y. Li, Stanford University, Stanford, CA) was amplified by PCR with the following primers: forward, gccACCGGTcatggtgagcaagggcgaggagaataacatggccatcatcaaggagttcatgcgc; and reverse, ggcGCTAGCcttgtacagctcgtccatgccgccggtggagtggcggcc. The DNA amplification products were then subcloned into TfR-SEP using AgeI/ NheI. Constructs were verified by restriction analysis and sequencing.

\section{Cell cultures and transfection}

Dissociated hippocampal neurons from embryonic day 18 rat embryos of either sex were prepared as described previously (Kaech and Banker, 2006) at a density of 150,000 cells per dish in Neurobasal medium supplemented with 2 mu glutamine and 10\% Neuromix (PAA Laboratories) or B27 (Gibco). Astrocytes were prepared from the same embryos, plated at 10,000 cells per dish, and cultured in MEM containing 10\% horse serum (Invitrogen) for $14 \mathrm{~d}$. NIH 3T3 (European Collection of Cell Cultures) cells were cultured in DMEM supplemented with $1 \%$ sodium pyruvate, $1 \%$ glutamate, and $10 \%$ fetal calf serum (Invitrogen).

Neurons and astrocytes were transfected at 6-14 d in vitro (DIV) with $2 \mu \mathrm{g}$ of total DNA, using Effectene (Qiagen) following the company protocol. For two-color experiments with Rab-mCherry proteins, cells were transfected $24 \mathrm{~h}$ before imaging (13-14 DIV) to limit cluster formation visible after $2 \mathrm{~d}$ of expression. Neurons transfected with TfR-SEP could also be electroporated before plating using a $4 \mathrm{D}$-Nucleofector (Lonza) according to the company protocol. This protocol was used to transfect TfR-SEP and monitor exocytosis on 7, 14, and 21 DIV neurons (see Fig. $2 E, F$ ). NIH 3T3 cells were transfected with $1 \mu \mathrm{g}$ of plasmid in 1 $\mathrm{ml}$ of optiMEM (Invitrogen) with $10 \mu \mathrm{l}$ of Lipofectamine 2000 (Invitrogen) before plating on polylysine-coated glass coverslips and imaged $24 \mathrm{~h}$ after transfection.

\section{Live-cell fluorescence imaging}

Live-cell imaging was done at $35-37^{\circ} \mathrm{C}$. Cells were perfused with HEPES buffered solution (HBS) with the following (in $\mathrm{mm}$ ): $120 \mathrm{NaCl}, 2 \mathrm{KCl}, 2$ $\mathrm{MgCl}_{2}, 2 \mathrm{CaCl}_{2}, 10 \mathrm{HEPES}$, and $5 \mathrm{D}$-glucose, adjusted to $\mathrm{pH} 7.4$ (265-280 mOsm). For experiments with 5 and 50 mM HEPES, the concentration of $\mathrm{NaCl}$ was adjusted to keep osmolarity constant.

Fluorescent cells were imaged with spinning-disk confocal, wide-field epifluorescence, or total internal reflection fluorescence (TIRF) microscopy. The spinning-disk confocal microscope consisted of a Leica DMI6000 inverted microscope (Leica) equipped with a Confocal Scanner Unit CSU22 (Yokogawa Electric Corporation), an HCX Plan Apo $63 \times$ oil-immersion objective [numerical aperture (NA) 1.4], and a QuantEM camera (Roper Scientific). Illumination was achieved by a 473 $\mathrm{nm}$ laser and, for two-color imaging, by alternating 473 and $532 \mathrm{~nm}$ lasers. The whole system was controlled by MetaMorph 7 software (Roper Scientific). For wide-field epifluorescence (for $\mathrm{pH}$ changes experiments) and TIRF (for trypan experiments) microscopy, we used an Olympus IX71 inverted microscope equipped with either a Zeiss Plan Fluar $100 \times$ oil-immersion objective (NA 1.45) or an Olympus apoN $60 \times$ oil-immersion objective (NA 1.49) plus a $1.6 \times$ lens. Epifluorescence illumination was done with either a xenon lamp (Olympus) with a 480/10 $\mathrm{nm}$ excitation filter or a $470 \mathrm{~nm}$ LED (Rapp Opto-Electronics). TIRF illumination was done with a 473 laser (Cobolt) through the Olympus TIRF illuminator. The camera was controlled by MetaVue (Roper Scientific).
For the solution exchange experiments, a theta pipette $(\sim 100 \mu \mathrm{m}$ tip size) was placed close to the recorded cell. It contained HBS, $\mathrm{pH} 7.4$, and a solution in which HEPES was replaced with MES (MBS) at pH 5.5 [pulsed $\mathrm{pH}(\mathrm{ppH})$ ] or containing $5 \mathrm{~mm}$ trypan purple (Interchim) in $\mathrm{HBS}$ at $\mathrm{pH}$ 7.4. Solution flow was alternated with electrovalves (Lee Company) in synchrony with image acquisition (Merrifield et al., 2005). Amiloride (500 $\mu \mathrm{M}$; Ascent Scientific) was added to HBS and MBS when indicated. For fast oscillating $\mathrm{pH}$ changes, the $\mathrm{pH} 7.8$ solution was buffered with HEPES, and the $\mathrm{pH} 6.8$ solution was buffered with PIPES (10 $\mathrm{mm}$ ). Dynasore and latrunculin A (Tocris Bioscience) were dissolved in DMSO and used at final concentrations of 80 and $10 \mu \mathrm{M}$, respectively. DMSO $(0.1 \%)$ was used for matching control recordings. Live immunolabeling of cells transfected with SEP- $\beta 2 \mathrm{AR}$ was performed using monoclonal anti-GFP (Roche clones 7.1 and 13.1), coupled to Cy3 using a reagent kit (GE Healthcare), diluted to 1:200 in culture medium. Cells were incubated at $37^{\circ} \mathrm{C}$ in culture medium for $10 \mathrm{~min}$ before washing in HBS and imaging of the cells.

\section{Patch-clamp recordings}

Recording pipettes (resistance, $5 \mathrm{M} \Omega$ ) were filled with a solution containing the following (in mM): $120 \mathrm{KCH}_{3} \mathrm{SO}_{3}, 2 \mathrm{NaCl}, 2 \mathrm{MgCl}_{2}, 10 \mathrm{EGTA}$, 10 HEPES, and $4 \mathrm{Na}_{2} \mathrm{ATP}$, adjusted to $\mathrm{pH} 7.2$ with $\mathrm{KOH}(260 \mathrm{mOsm})$. Cells were recorded in the same conditions as for fluorescence imaging and voltage clamped at $-60 \mathrm{mV}$ with an EPC10 patch-clamp amplifier (Heka).

\section{Image analysis}

Detection of events. To highlight fast fluorescence increases reporting exocytosis events, we first constructed a differential movie (image ${ }_{n+1}-$ image $_{n}+$ constant). A manual threshold was used to select candidate events (objects bigger than 2 pixels), with additional criteria to exclude moving clusters, variations in intense clusters, or tubule contraction. For each candidate event, a mini-movie and a series of backgroundsubtracted images were generated. Events were validated or discarded by the user based on these two visualization tools. For experiments with fast $\mathrm{pH}$ changes, events were detected directly on the full movie. Event frequencies were normalized by the surface of the cell mask.

Fluorescence quantification. For fluorescence quantification, a region of interest (ROI) and a region surrounding the ROI (SR) are defined as follows. The five background-subtracted images before exocytosis define an SD of pixel values. A threshold is defined as seven times the SD to define putative ROIs (Fig. 1B). In case of multiple objects, the one closest to image center is chosen. If no object is detected, the ROI is defined as a 2.2 pixel $(380 \mathrm{~nm})$ radius circle centered on the centroid of the original detection. If an object is detected, the ROI is the reunion of the object and a 2.2 pixel radius circle centered on the object. The SR is obtained by a dilation of the ROI by 2 pixels (Fig. $1 B$ ). For the following frame, the same object detection procedure is applied, and a new ROI and SR are defined. The centroid of the new ROI must be $<5$ pixels away. If no object is defined, the ROI is kept the same. For images before exocytosis, the ROI used is the one defined at time 0 , the time of exocytosis. Length is defined as the major axis length of the ellipse fitted to the object detected. If no object is detected at the moment of exocytosis, length is set to a minimum of $760 \mathrm{~nm}$.

For each event, we compute $F_{\mathrm{R}-\mathrm{s}}=F_{\mathrm{ROI}}-F_{\mathrm{SR}}$, where $F_{\mathrm{ROI}}$ and $F_{\mathrm{SR}}$ represent the average fluorescence of the original images in the ROI and the SR, respectively. For the SR, the 20\% lowest and highest pixel values are removed to limit environmental variations (out of the cell, bright cluster). For each event, $F_{\mathrm{R}-\mathrm{S}}$ is normalized by subtracting the average of values before exocytosis and divided by $F_{\mathrm{R}-\mathrm{s}}$ at the time of exocytosis. Events for which normalized $F_{\mathrm{R}-\mathrm{s}}$ was $>50 \%$ for $<2 \mathrm{~s}$ were sorted as burst events, and the other ones were sorted as display events. For oscillating $\mathrm{pH}$ experiments (see Fig. 4), the ROI was defined manually, and the SR was adjusted to minimize variations in $F_{\mathrm{R}-\mathrm{s}}$ before exocytosis.

For two-color experiments, red $F_{\mathrm{R}-\mathrm{s}}$ is quantified with the same ROI and SR defined with the SEP signal. The fluorescence is normalized by the average red fluorescence in the cell to limit variations between cells attributable to differences in expression levels. To esti- 
A
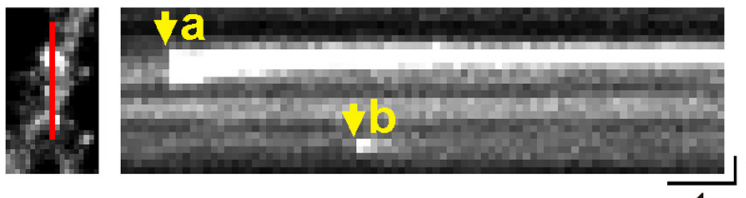

B a

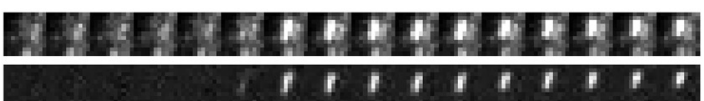
O00000000000DDDD
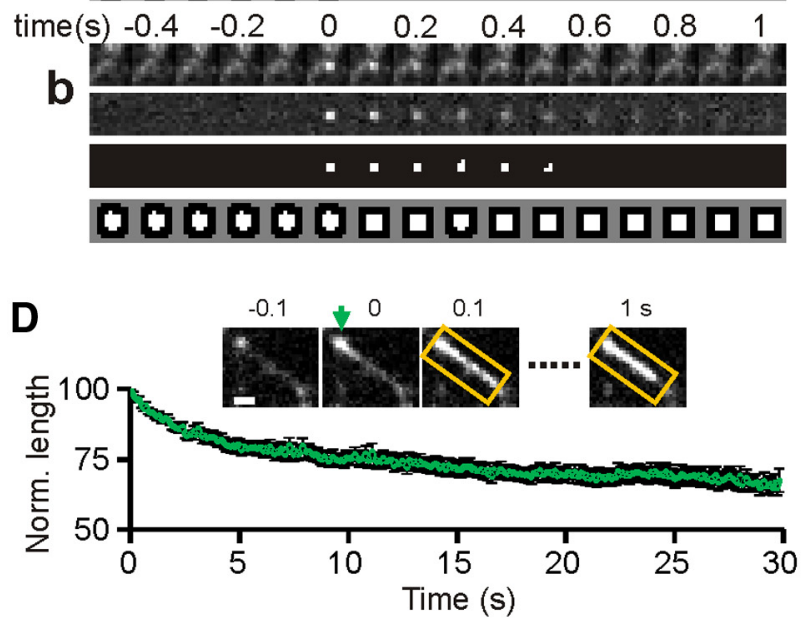

Ca

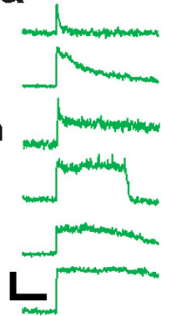

b

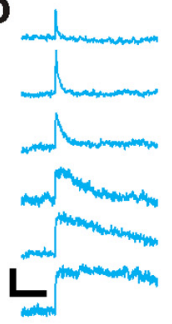

c

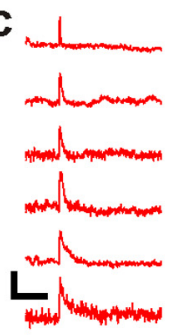

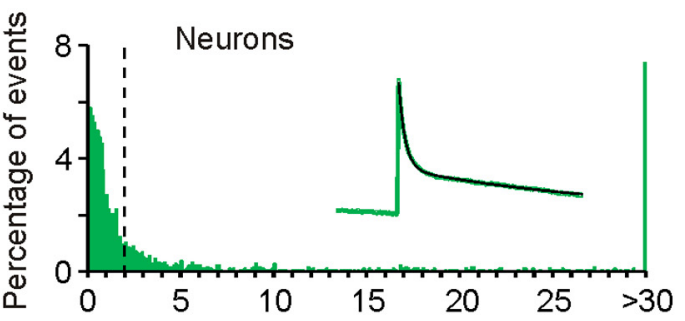
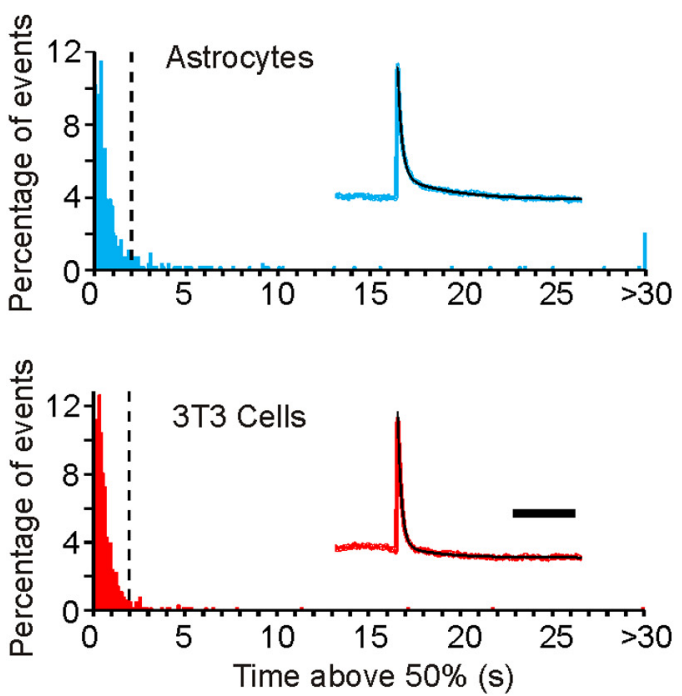

Figure 1. Two types of exocytosis of TfR-containing organelles in the somatodendritic compartment of neurons. $\boldsymbol{A}$, Portion of a neuronal dendrite (14 DIV) showing two exocytic events. Kymograph from the line scan on the left region shows an event in which the tubular organelle remains visible for many seconds (display event, $\boldsymbol{a}$ ) and another event in which receptors quickly diffuse in the plasma membrane after exocytosis (burst event, $\boldsymbol{b}$ ). $\boldsymbol{B}$, Illustration of the quantification of fluorescence during exocytosis events $\boldsymbol{a}$ and $\boldsymbol{b}$ shown in $\boldsymbol{A}$. First row, Consecutive raw images. Time 0 indicates exocytosis. Second row, Images minus the average of five images before exocytosis. The exocytosis event is seen in isolation. Third row, Pixels above threshold define objects. In event $\boldsymbol{b}$, no object is detected after 0.6 s. Fourth row, ROI and SR are calculated as explained in Materials and Methods. $\boldsymbol{C}$, Left, Quantification of single events recorded in neurons ( $\boldsymbol{a}$ : 1760 events, 8 cells, 14-15 DIV), astrocytes ( $\boldsymbol{b}$ : 539 events, 15 cells), and NIH 3T3 cells ( $\boldsymbol{c}: 633$ events, 9 cells). Calibration: 100 AU, 10 s. Right, Histograms of the time the background subtracted fluorescence remains above half of initial fluorescence, for the three cell types. The stippled lines define the $2 \mathrm{~s}$ threshold to sort burst and display events. Note the large proportion of events visible for $>30$ s in neurons. Insets, Average fluorescence of exocytosis events. Black lines show biexponential fits of the curves (see Materials and Methods). $\boldsymbol{D}$, Top, Example of a large tubular compartment undergoing exocytosis (green arrow). Note the site of initiation of fluorescence rise on the side of the tubule and the contraction $1 \mathrm{~s}$ after exocytosis (yellow box). Scale bar, $1 \mu \mathrm{m}$. Bottom, Evolution of organelle length with time in neurons, normalized to length at start of event. Organelles visible for $>2 \mathrm{~s}$ were considered for this analysis.

mate the level of enrichment of red fluorescent markers, we cotransfected neurons with TfR-SEP and mCherry, a cytosolic protein. With our quantification and normalization method, we detected no variation of mCherry fluorescence after exocytosis and a level of average normalized fluorescence of $\sim 1.20$ for display and 1.26 for burst exocytosis (see Fig. 6F). Therefore, we took as significant enrichment average measures over 1.3.

For the fluorescence diffusion calculation (Fig. 2D,E), total intensity was calculated in the ROI, in a 2-pixels-wide annulus 1 pixel away from the ROI (SR1) and in a 2-pixels-wide annulus 3 pixels away from the ROI (SR3). Photobleaching was corrected in each cell according to the decrease of the average fluorescence before exocytosis. For each event, the fluorescence is normalized in the different regions: the average value of fluorescence in the $10 \mathrm{~s}$ before exocytosis is subtracted, and the intensity at the time of exocytosis in the central ROI is set to $100 \%$. This value is used to divide the total intensity in SR1 and SR3.

\section{Estimation of the proportion of display events with different imaging frequencies}

Continuous recordings (Fig. 1A) clearly show that some burst events are detectable for $1 \mathrm{~s}$ or less. It is likely that, during $1 \mathrm{~Hz}$ time-lapse imaging, only part of the burst events are detected. We have simulated time-lapse imaging at $1 \mathrm{~Hz}$ by taking 1 of 10 images in continuous recordings at 10 $\mathrm{Hz}$. In these recordings, we detected $82.6 \pm 3.7 \%$ of the events detected in the whole continuous recording ( $n=8$ cells). The proportion of display events $P_{\mathrm{dp}}$ goes from $33 \%$ (in continuous recordings) to $42 \%$ in simulated time lapse, close to the values found in actual time-lapse recordings $(40-47 \%)$. The missed events are all burst events, so the proportion of detected burst events $\beta$ is such that $P_{\mathrm{dp}}+\beta P_{\mathrm{bs}}=0.83$, with $P_{\mathrm{bs}}=1-P_{\mathrm{dp}}$ the proportion of burst events. We get $\beta=74 \%$. Therefore, in $1 \mathrm{~Hz}$ time-lapse recordings, we can detect approximately three-quarters of burst events and estimate accurately the proportion of each type of event.

In experiments with the $\mathrm{ppH}$ protocol, the acquisition rate at $\mathrm{pH} 7.4$ is $0.25 \mathrm{~Hz}$ (one image at $\mathrm{pH} 7.4$ interleaved with one image at pH 5.5 every $2 \mathrm{~s}$ ). If we consider that a burst event can be detected at $1 \mathrm{~Hz}$ only for one frame, then at $0.25 \mathrm{~Hz}$ four times less events will be detected, i.e., a proportion of $\beta^{\prime}=0.74 / 4=0.18$. The apparent proportion of burst events during $0.25 \mathrm{~Hz}$ imaging will be $\beta^{\prime} P_{\mathrm{bs}} /\left(P_{\mathrm{dp}}+\beta^{\prime} P_{\mathrm{bs}}\right)=0.26$. This proportion is only slightly smaller than the maximum proportion of events that are not kiss-and-run events (35\%; Fig. 3C). We can conclude from this estimate that the vast majority ( $88 \%$ ) of display events recorded with TfR-SEP are kiss-an-run events.

\section{Statistical procedures}

All data are presented as mean \pm SEM. Statistical significance was calculated between interleaved control cells and test cells using a Student's two-tailed $t$ test, unless otherwise indicated. Averages of display and burst events in 5 and $50 \mathrm{~mm}$ HEPES were compared by a permutation test on the sum of squared differences. 

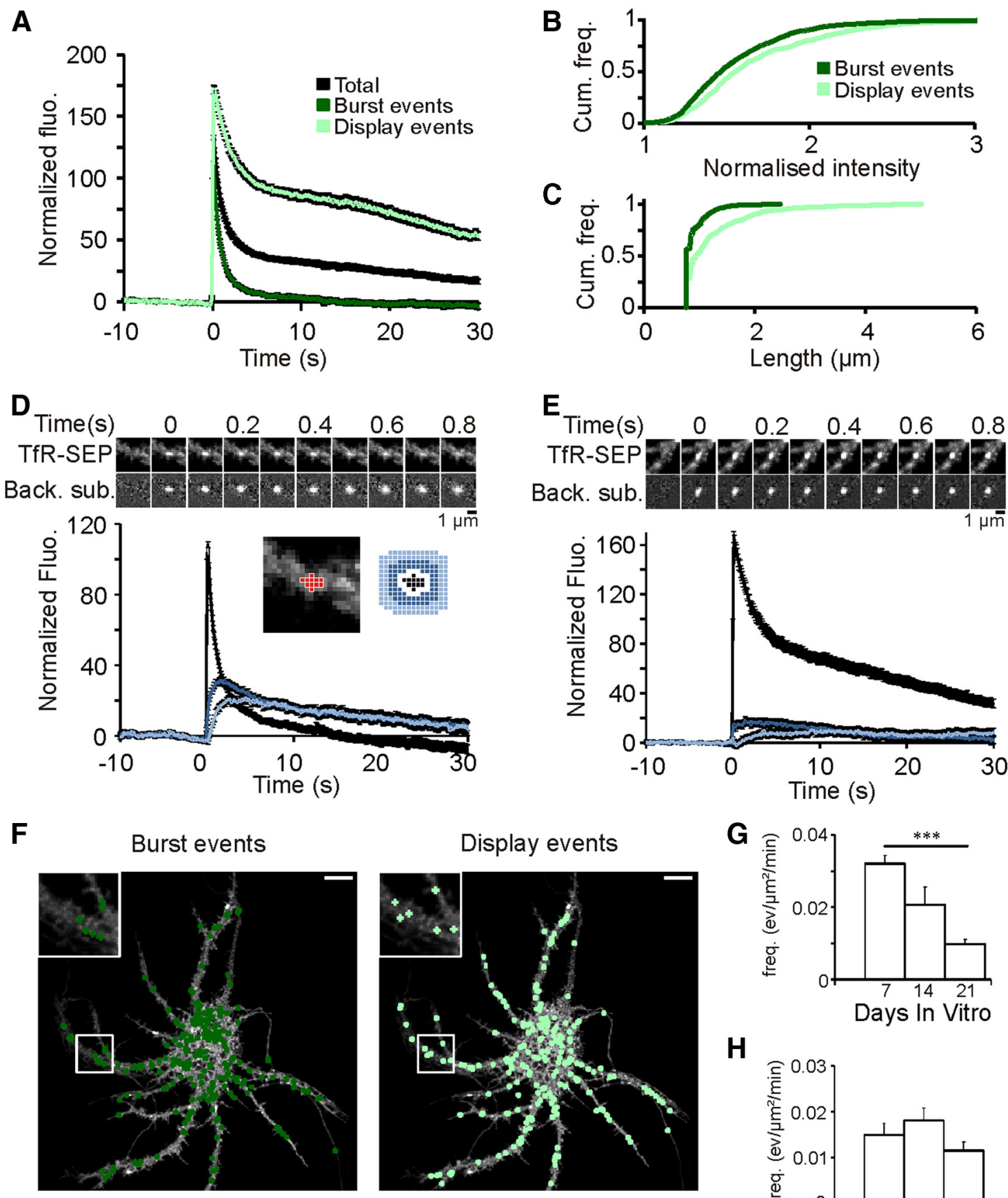

Days In Vitro

H

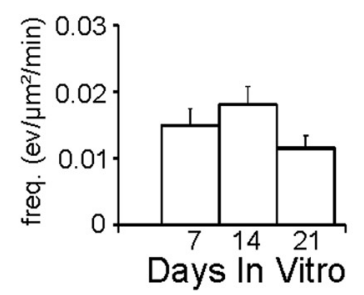

Figure 2. Properties of burst and display events in neuronal dendrites. $A$, Average of exocytosis events (black curve) recorded in $14-15$ DIV neurons ( $n=8)$, sorted in burst (dark green, 1139 events) and display (light green, 621 events). $\boldsymbol{B}, \boldsymbol{C}$, Maximal fluorescence $(\boldsymbol{B})$ and length $(\boldsymbol{C})$ of burst and display events. $\boldsymbol{D}, \boldsymbol{E}$, Diffusion of receptors after exocytosis. Total fluorescence measured in ROI (black), SR1 (dark blue), and SR3 (light blue) (see Materials and Methods), depicted in the scheme (inset), for burst events (D) and display events (E). Top, Consecutive images of example events. Raw images on top, background subtracted below. Scale bar, $1 \mu \mathrm{m}$. $\boldsymbol{F}$, Map of the burst $(n=226)$ and display $(n=218)$ events detected on a neuron (14 DIV) during a 5 min movie at $1 \mathrm{~Hz}$. Scale bar, $10 \mu \mathrm{m} . \mathbf{G}, \boldsymbol{H}$, Frequency of burst $(\boldsymbol{G})$ and display $(\boldsymbol{H})$ events recorded with $1 \mathrm{~Hz}$ imaging. Burst event frequency decreases with age in culture (significant difference between 7 and 21 DIV neurons, ${ }^{* * *} p<0.001$ ) but not display event frequency $(\boldsymbol{H})$.

\section{Results}

Two types of exocytosis events in neuronal dendrites

To investigate fundamental parameters of RE exocytosis in neurons, we have imaged with spinning-disk confocal microscopy at $10 \mathrm{~Hz}$ cultured hippocampal neurons transfected with TfR-SEP, a general marker of REs (Park et al., 2006; Kennedy et al., 2010; Puthenveedu et al., 2010). Single exocytosis events were detected throughout the somatodendritic compartment at a frequency of $0.069 \pm 0.012$ events $/ \mathrm{min} / \mu \mathrm{m}^{2}$ ( $n=8$ neurons, $\left.15 \mathrm{DIV}\right)$. After exocytosis, receptors either quickly disappear or remain clustered and visible for many seconds (Fig. $1 A$ ). We quantified the duration of each event, i.e., the time its average fluorescence (Fig. $1 B$; for quantification, see Materials and Methods) remains $>50 \%$ of its initial value. The values were spread widely, from $<1$ to $>30 \mathrm{~s}$ 

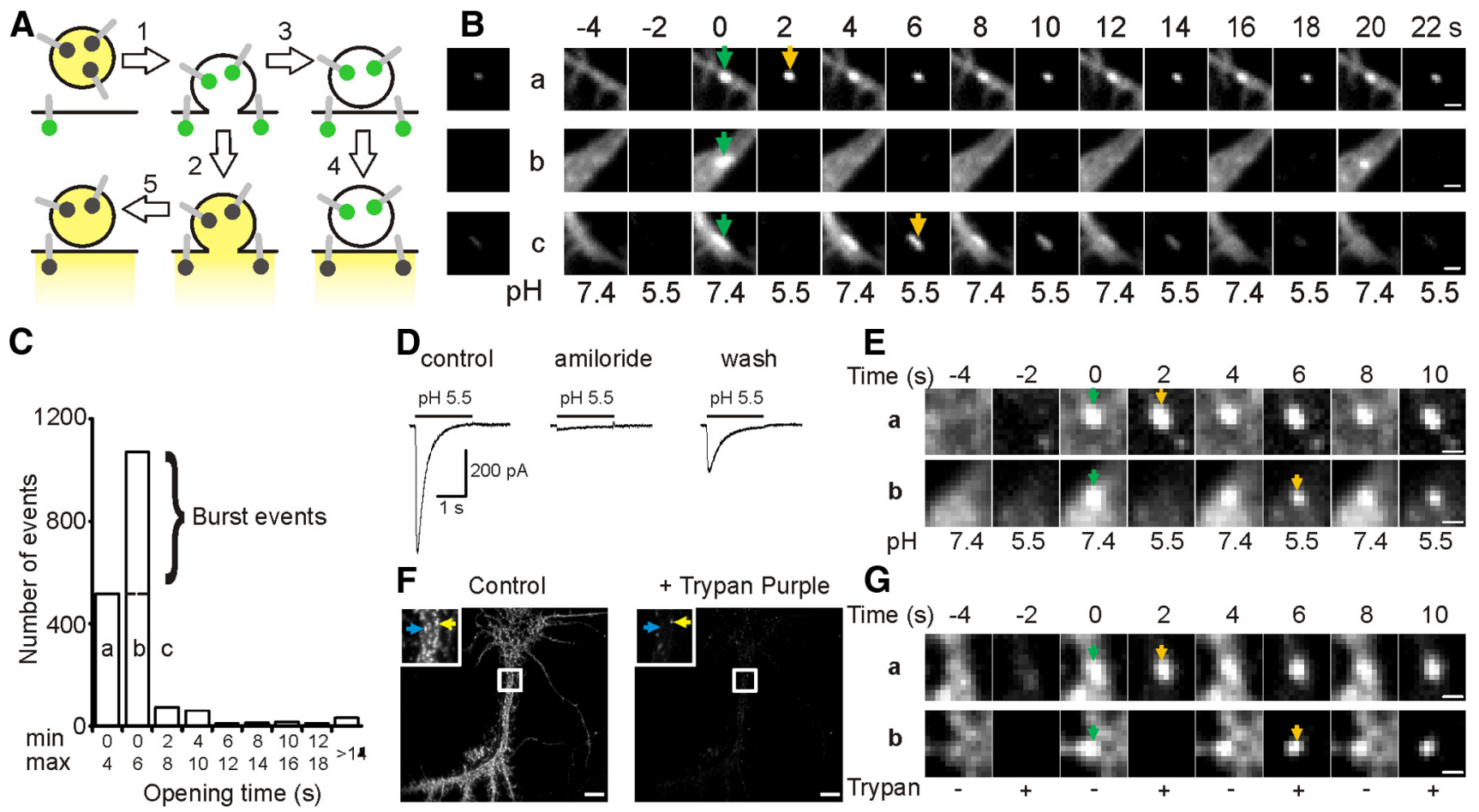

Figure 3. Display events are attributable to fast retrieval of receptors after exocytosis. $\boldsymbol{A}$, Principle of pH changes to detect internalized receptors. Acidic solution (pH 5.5) is yellow, fluorescent receptors are green, and nonfluorescent receptors are black. At pH 7.4, receptors are fluorescent after exocytosis (1), but if they remain on the plasma membrane they will not be fluorescent at pH 5.5 (2). Alternatively, if they are internalized again at pH 7.4 (3), they will remain fluorescent when extracellular pH is switched to $\mathrm{pH} 5.5$ (4). If they are internalized at pH 5.5 , they will remain invisible (5). $\boldsymbol{B}$, Three types of events recorded in neurons expressing TfR-SEP at $0.5 \mathrm{~Hz}$ with alternate extracellular pH changes. Right, Images at pH 5.5 at $2 \times$ contrast for clarity. Exocytosis 0 ccurs at time 0 (green arrows). In $\boldsymbol{a}$, a cluster is visible at pH 5.5, $2 \mathrm{~s}$ after exocytosis (yellow arrow). In $\boldsymbol{b}$, no cluster is visible at pH 5.5. However, a second event is seen $20 \mathrm{~s}$ after the first. It could report a second exocytosis after closure at pH 5.5. In c, a cluster is visible $6 \mathrm{~s}$ after exocytosis (yellow arrow). Note the difference in the kinetics of fluorescence decrease between $\boldsymbol{a}$ and $\mathbf{c}$. Left, Images at pH 5.5 (2, 2 , and 6 s for events $1-3$, respectively) are presented at the same contrast as the pH 7.4 images. Scale bar, $1 \mu \mathrm{m}$. $\boldsymbol{C}$, Histogram of events of the three types described in $\boldsymbol{B}$, with estimated opening time, i.e., the minimal and maximum interval between exocytosis and internalization. Dotted line shows the lower limit for the proportion of events of type $b$ being kiss-and-run events. $\boldsymbol{D}$, Patch-clamp recording of a neuron during the application of solution at pH 5.5. The current evoked (peak amplitude of $560 \pm 90 \mathrm{pA}, n=3$ ) is blocked by $500 \mu \mathrm{m}$ amiloride ( $92 \pm 8 \%$, same cells). $\boldsymbol{E}$, Examples of events detected as in Figure $2 B$ showing pH 5.5 resistant fluorescent clusters (yellow arrows) $2 \mathrm{~s}(\boldsymbol{a})$ and $6 \mathrm{~s}(\boldsymbol{b})$ after exocytosis is detected (green arrows) in the presence of amiloride $(500 \mu \mathrm{m})$. Fifty-eight such events were detected in eight cells. Images at pH 5.5 are shown at $2 \times$ contrast. Scale bar, $1 \mu \mathrm{m}$. F, Neuron transfected with TfR-SEP, before (left) and $2 \mathrm{~s}$ after application of trypan purple ( $5 \mathrm{~mm}$ ). Most of the SEP fluorescence is quenched, similar to pH 5.5 perfusion. A dendritic region is highlighted, showing two clusters, one completely quenched (blue arrow) and another one still visible, revealing internalized TfR-SEP (yellow arrow). Scale bar, $10 \mu \mathrm{m}$. $\mathbf{G}$, Examples of kiss-and-run events with a protocol similar to ppH but in which the pH 5.5 solution is replaced by a solution containing trypan purple. Clusters are visible in trypan purple $2 \mathrm{~s}(\boldsymbol{a})$ or $6 \mathrm{~s}(\boldsymbol{b})$ after exocytosis. A total of 163 such events were detected in seven cells. Images with trypan purple are shown at $2 \times$ contrast. Scale bar, $1 \mu \mathrm{m}$.

(Fig. 1Ca). To determine whether these characteristics were specific to neurons, we imaged astrocytes and NIH $3 \mathrm{~T} 3$ cells, a mouse fibroblast cell line. Exocytic events occurred at much lower frequencies of $0.0056 \pm 0.0018$ events $/ \mathrm{min} / \mu \mathrm{m}^{2}(n=15$ astrocytes) and $0.018 \pm 0.003$ events $/ \mathrm{min} / \mu \mathrm{m}^{2}(n=9 \mathrm{NIH} 3 \mathrm{~T} 3$ cells). Long-duration events were much rarer in astrocytes and virtually absent in NIH 3T3 cells (Fig. $1 C b, C c$ ). The average fluorescence traces (Fig. 1C) can be fitted with the sum of two exponential functions with fast $(1.1,0.7$, and $0.62 \mathrm{~s})$ and slow (51.2, 8.6, and $6.6 \mathrm{~s}$ ) decays for neurons, astrocytes, and NIH 3T3 cells, respectively. The contribution of a slow component was much higher for neurons (36\%) than for astrocytes (16\%) and NIH 3T3 cells $(7 \%)$. Moreover, in neurons, many organelles undergoing exocytosis were of tubular shape with lengths up to several micrometers (average length, $0.99 \pm 0.01 \mu \mathrm{m}$ ). Tubules often contracted immediately after exocytosis, on average, to $80 \pm 2 \%$ their initial length after $5 \mathrm{~s}$ (Fig. 1D). Tubular shapes were much rarer in astrocytes and were not seen in NIH $3 \mathrm{~T} 3$ cells.

In NIH 3 T3 cells, the vast majority of events (94\%) lasted $<2$ $\mathrm{s}$, revealing a homogenous population of events. This gave us a simple criterion to distinguish long events, i.e., $>2 \mathrm{~s}$ (Fig. $1 C$, stippled lines), which we shall call display events hereafter. Dis- play events have been described and named persistent events in previous studies (Yudowski et al., 2006, 2007), but we have changed the terminology to avoid confusion on their likely mechanisms (see below). Display events accounted for $33 \pm 4 \%$ of events in neurons $(n=8)$ and $15 \pm 4 \%$ of events in astrocytes $(n=15)$. The average fluorescence of short events, which we shall name burst events, matches the average of exocytic events seen in other cells, whereas the average of display events is biphasic (Fig. $2 A$ ). Display events corresponded to slightly brighter (Fig. 2B) and longer (Fig. 2C) organelles than burst events. For burst events, fast fluorescence decay indicated diffusion in the plasma membrane (Fig. 2D). Effectively, quantification of fluorescence in concentric annular regions around the main ROI showed a pattern of exponential decays with increasing time constants, consistent with diffusion. For display events, the total fluorescence time course in the ROI was biphasic (Fig. 2E). Fluorescence increase in annular regions was consistent with a small diffusive component in the first seconds. The fluorescence decay in the ROI between 5 and $30 \mathrm{~s}$ was not accompanied by an increase in flanking regions, as it would be expected for diffusing receptors. Therefore, after display events, most of the receptors probably 
remain at the site of exocytosis, despite the fluorescence decrease observed.

We performed long recordings ( $1 \mathrm{~Hz}$ time lapse) to map exocytic events. Both types of events occurred throughout the somatodendritic tree (Fig. $2 F$ ) but very little in dendritic spines, if any. At this recording frequency, some burst events are missed (see Materials and Methods), leading to a higher apparent proportion of display events ( $48 \pm 3 \%, n=9)$. The event frequency was higher in the soma than in the dendrites $(0.057 \pm 0.009$ vs $0.030 \pm 0.005$ in soma and dendrites, respectively, ${ }^{* *} p<0.01$ ), but the proportion of display events was similar in both compartments $(0.43 \pm 0.03$ vs $0.50 \pm 0.03$ in soma and dendrites, respectively). Finally, exocytosis frequency decreased with age in culture $\left(0.047 \pm 0.0045 \mathrm{vs} 0.021 \pm 0.0025 \mathrm{events} / \mathrm{min} / \mu \mathrm{m}^{2}\right.$ at 7 and 21 DIV, respectively), but this decrease was selective for burst events (Fig. 2G,H), suggesting developmental regulation of TfR recycling and exocytosis mechanisms.

\section{Display events signal fast fusion pore opening and closing}

What could be the mechanism responsible for display events? This behavior could be attributable to restricted diffusion in the plasma membrane, as suggested for other receptors (Yudowski et al., 2006; Kennedy et al., 2010; Yu et al., 2010), or to fast retrieval of receptors after exocytosis, a mechanism often referred to as "kiss-and-run" and observed for secretory vesicles (Alés et al., 1999; Taraska et al., 2003; Elhamdani et al., 2006; Jaiswal et al., 2009). To discriminate between these two possibilities, we applied a solution at $\mathrm{pH} 5.5$ for $2 \mathrm{~s}$ every $4 \mathrm{~s}$ and recorded images at $0.5 \mathrm{~Hz}$ in synchrony. This protocol, that we name $\mathrm{ppH}$, was originally designed to study clathrin-mediated endocytosis (CME; Merrifield et al., 2005). At pH 5.5, receptors on the plasma membrane are not fluorescent, whereas internalized receptors in notyet-acidic compartments remain fluorescent (Fig. $3 A$ ). Events recorded during ppH (1803 events in 38 cells) demonstrate closure of a fusion pore within seconds. They exhibit three main behaviors (Fig. 3B): (a) in the frame following exocytosis, a cluster is visible at $\mathrm{pH} 5.5$ at the site of exocytosis; (b) no cluster is visible at pH 5.5 after exocytosis; and (c) the cluster is not visible in the first frame after exocytosis but appears in one of the following pH 5.5 frames. Possibilities a and c unambiguously indicate that all or part of receptors is internalized within seconds after exocytosis because fluorescence is resistant to the extracellular acidic environment. In type a, the interval between exocytosis and internalization ranges from 0 to $4 \mathrm{~s}$ : exocytosis occurs just after frame $-4 \mathrm{~s}$ and closure just after frame 0 . However, it could be argued that receptor appearance is not related to exocytosis. In cells continuously perfused with low $\mathrm{pH}$ solution, we did not observe any such events, confirming that events of type a report exocytosis. In type $\mathrm{c}$, the frame with no fluorescence at $\mathrm{pH}$ $5.5(+2 \mathrm{~s})$ shows that receptors are on the plasma membrane (i.e., have been exocytosed) but are then internalized after a delay of $2-8 \mathrm{~s}$ (Fig. 2C). Events as in type b could correspond to burst events or to events in which receptors are internalized at $\mathrm{pH}$ 5.5. The delay between exocytosis and internalization is thus between 0 and $6 \mathrm{~s}$, encompassing the interval estimated for type a events $(0-4 \mathrm{~s})$. Therefore, there should be at least as many fusion pore closure events in type b as in type 1 (Fig. $2 C$, dotted line). This implies that, in all recorded events during this protocol, at least $63 \%$ of events signal fusion pore closure, or kiss-and-run. Moreover, the apparent proportion of burst events during $\mathrm{ppH}$ is estimated at 26\% (see Materials and Methods). Consequently, at least $63 /(1-0.26)=85 \%$ of display events are kiss-and-run events, with a fusion pore remaining open for $<6 \mathrm{~s}$ in $90 \%$ of events. The application of low $\mathrm{pH}$ solution does not affect CME (Merrifield et al., 2005; Taylor et al., 2011) but could artificially provoke receptor internalization after exocytosis. Indeed, $\mathrm{ppH}$ evokes large inward currents that are blocked by amiloride (500 $\mu \mathrm{M}$ ), a blocker of acid-sensing ion channels (Xiong et al., 2004; Fig. 3D). Application of amiloride did not affect the appearance of clusters at pH 5.5 (Fig. 3E). Moreover, we searched for an alternative method to detect receptor internalization. We found that SEP can be efficiently and reversibly quenched by trypan purple (Fig. $3 F$ ). Application of trypan purple $(5 \mathrm{~mm})$ revealed events with fusion pore closure, similar to the ones seen with low $\mathrm{pH}$ (Fig. $3 G$ ). In conclusion, the $\mathrm{ppH}$ protocol does not induce fusion pore closure, and the majority of display events reported with TfR-SEP, if not all, corresponds to fast opening and closing of exocytosis fusion pore.

To measure the opening duration of display events more precisely, we adapted the $\mathrm{ppH}$ protocol to monitor the fluorescence under fast $\mathrm{pH}$ changes. We alternated between solutions at $\mathrm{pH}$ 6.8 and 7.8 , the $\mathrm{pH}$ interval at which SEP fluorescence varies most (Sankaranarayanan et al., 2000), with a 400 ms cycle. In this condition, the fluorescence of receptors on the plasma membrane oscillates and is markedly different in successive frames. After display exocytosis, receptor fluorescence in the compartment also oscillates until closure of the fusion pore (Fig. 4A). For 154 events ( $n=29$ cells), the opening time distribution is positively skewed with a median of $2.6 \mathrm{~s}$ (Fig. $4 B$ ). This distribution is compatible with the estimate made before with the $\mathrm{ppH}$ protocol (Fig. 3C). Examples in Figure $4 C$ illustrate the diversity of observed behaviors. In type a, after a short opening $(0.7 \mathrm{~s})$, the organelle remains static for $11 \mathrm{~s}$ and then opens again. Note that the fluorescence remains stable between the two events. The closure would have remained undetected without the $\mathrm{pH}$ changes. Types b and c show two of the longest openings observed, but in type b we observe little fluorescence decrease whereas it steadily decreases in type c, suggesting different degrees of restricted diffusion through a fusion pore. In conclusion, fusion pores show a wide range of opening times and restriction to receptor diffusion.

Diffusion of receptors is restricted after display exocytosis, but is the ligand specifically released? To test this, we incubated transfected neurons with transferrin conjugated with Alexa Fluor $568(\mathrm{Tfn}-\mathrm{A} 568 ; 50 \mu \mathrm{g} / \mathrm{ml})$ for $10 \mathrm{~min}$ and performed two-color confocal imaging. Tfn-A568 was enriched $\sim 1.5$-fold at sites of exocytosis and lost immediately after for burst events but retained for display events (Fig. 5A,B). Therefore, fusion pore opening during display events restricts the diffusion of TfR and its soluble cargo. Moreover, after fusion pore closure, the fluorescence would decrease because of endosome acidification. To test this possibility, we recorded events in solutions buffered with 5 or 50 mM HEPES. Fluorescence decay of burst events was not changed (Fig. 5C), whereas the fluorescence decay of display events was slightly but significantly faster at $5 \mathrm{~mm}$ than at $50 \mathrm{~mm}$ HEPES (Fig. 5D). Therefore, fluorescence decay of display events reflects organelle acidification after fusion pore closure. However, the kinetics of acidification varies widely among events. In Figure $3 B$, an organelle acidifies in $12 \mathrm{~s}$ (type $\mathrm{c}$ ), but another one remains neutral for $>20 \mathrm{~s}$ (type a). In the event shown in Figure $5 E$, fluorescence remains constant for $15 \mathrm{~s}$ after display exocytosis and then decays steadily for $8 \mathrm{~s}$ before burst exocytosis occurred for the same organelle. Therefore, the initiation of acidification is likely to be regulated. 

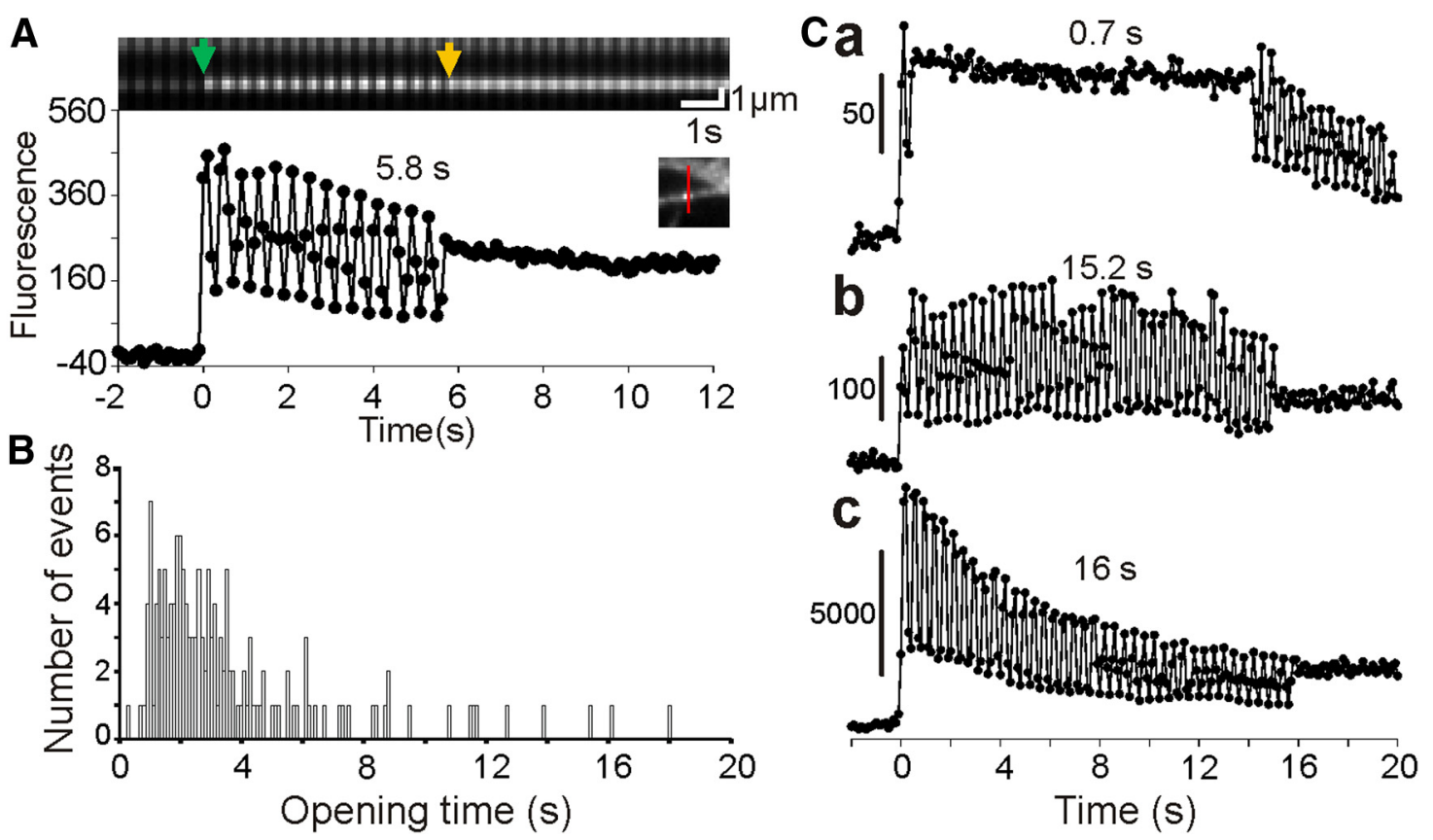

Figure 4. Measure of fusion pore open time during display events. $A$, Event recorded at $10 \mathrm{~Hz}$ with external solution oscillating between pH 6.8 and 7.8 with a period of $400 \mathrm{~ms}$. Top, Kymograph from the line scan (red line, inset) shows a display event. Fluorescence changes in synchrony with pH both for plasma membrane receptors and receptors after exocytosis (green arrow). After $\sim 15$ cycles, the fluorescence stops oscillating (orange arrow). Bottom, Quantification of background-subtracted average fluorescence. It oscillates at time 0 and stops oscillating 5.8 s later. $\boldsymbol{B}$, Histogram of opening times determined as in $\boldsymbol{A}$ for 154 events in 29 cells. C, Examples of events quantified as in $\boldsymbol{A}$. The measured open time is indicated. For comments, see Results.

\section{Involvement of Rab proteins in RE exocytosis}

The experiments described above show that the organelles undergoing display and burst exocytosis mediate receptor recycling. We tested the involvement of Rab4, Rab5, Rab8, Rab11, and Rab35, markers of the recycling pathway (Stenmark, 2009). Overexpression of dominant-negative (DN) forms of these proteins affects synaptic plasticity and spine development (Park et al., 2004, 2006; Brown et al., 2005, 2007; Petrini et al., 2009). Overexpressed Rab-mCherry proteins had a partially punctuate distribution in neurons and did not affect parameters of TfR-SEP exocytosis (Fig. 6A-C). The spatiotemporal alignment of $>1000$ exocytosis events sorted into burst and display allowed a quantitative measure of protein enrichment at the time of exocytosis. The marker of REs, Rab11, involved in receptor recycling and synaptic plasticity (Park et al., 2004; Brown et al., 2007), is enriched before exocytosis (Fig. $6 D, E$ ). It is present at all times before exocytosis and selectively retained after display exocytosis (Fig. 6Da), but it is discarded within seconds after burst exocytosis. In contrast, the early endosome marker Rab5-mCherry was not enriched at sites of exocytosis, nor was the marker of fast recycling Rab4-mCherry (Fig. $6 F$ ). Rab8 has been involved in late stages of AMPA receptor exocytosis and synaptic plasticity (Gerges et al., 2004; Brown et al., 2007). Rab8-mCherry is not enriched in REs before exocytosis, but some gradual recruitment was observed after display exocytosis specifically. Similarly, Rab35-mCherry, also involved in fast recycling (Kouranti et al., 2006), was enriched within seconds and persisted after display events, whereas no enrichment was observed for burst events (Fig. 6F).

Based on these observations, we examined the effects of perturbing the function of Rab11 and Rab35 on RE exocytosis. Perturbation of Rab35 function by overexpressing DN (Rab35 S22N, Rab35DN) and constitutively active (CA; Rab35 Q67L, Rab35CA) forms did not significantly affect the general parameters of TfR-SEP exocytosis (Fig. 6G,H). However, cells trans- fected with mutated Rab11 exhibit striking phenotypes. With Rab11CA (Rab11 Q70L), the frequency of display events decreased by more than half, whereas the frequency of burst events was not changed. Conversely, expression of Rab11DN (Rab11 $\mathrm{S} 25 \mathrm{~N}$ ) did not affect the frequency of display events but decreased significantly the frequency of burst events (Fig. 6G,H). Moreover, tubule length was significantly decreased by overexpression of Rab11CA, and the opposite effect was observed in cells expressing Rab11DN (Fig. 6I). This could reflect the continuous growth of REs that is curtailed in cells expressing Rab11CA. Conversely, in cells expressing Rab11DN, RE growth is not compensated by full-collapse fusion into the plasma membrane. These results indicate that Rab11 is involved in the final steps of receptor recycling, with the active, GTP-bound form enabling burst exocytosis.

\section{Dynamin and actin are not involved in the mechanism of} display events

The large GTPase dynamin, most well known for its role in CME (Ferguson and De Camilli, 2012) has been involved in fast retrieval after exocytosis in a number of secretory vesicles, including dense-core vesicles (Artalejo et al., 2002; Holroyd et al., 2002), synaptic vesicles (Watanabe et al., 2013), and trans-Golgi carriers (Jaiswal et al., 2009). To determine its involvement in kiss-andrun of REs, we applied the dynamin inhibitor dynasore (Macia et al., 2006). Application of dynasore $(80 \mu \mathrm{M})$ induced a rapid decrease in RE exocytosis frequency with an almost complete block in $<5$ min (Fig. $7 A$ ), whereas control vehicle (0.1\% DMSO) induced only a modest decrease in exocytosis frequency $(79 \pm 14 \%$ after $4 \mathrm{~min}, n=4)$. This could be attributable to the fast depletion of recycled TfR after blocking CME. Nevertheless, burst and display exocytosis events were equally rapidly blocked, and the proportion of display events was similar before and during block by dynasore (Fig. $7 B$ ). This result strongly suggests that dynamin is not involved in RE display endocytosis. However, apart from 
Aa
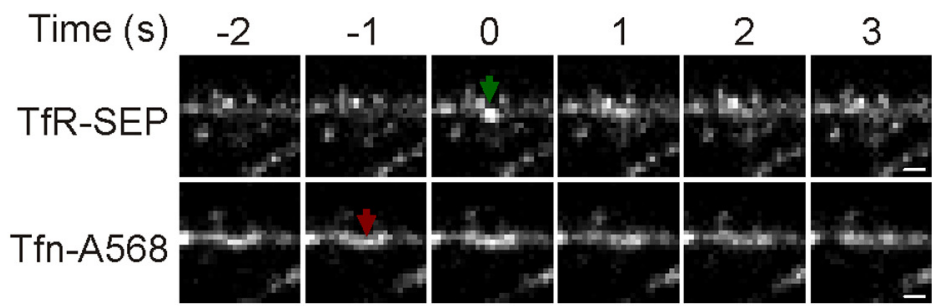

b
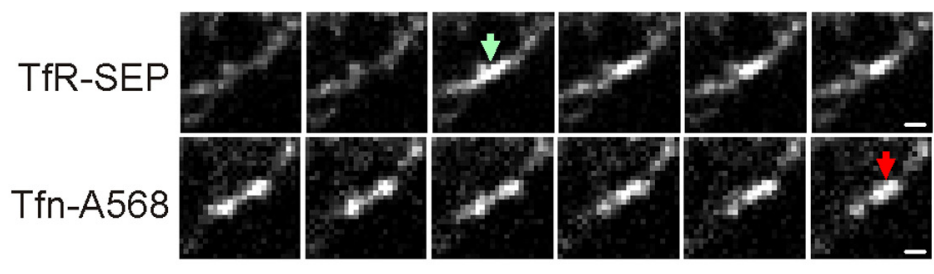

B
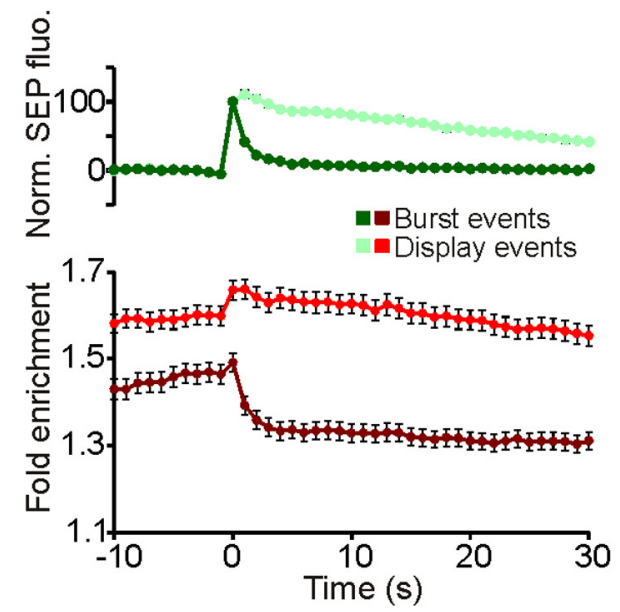

C

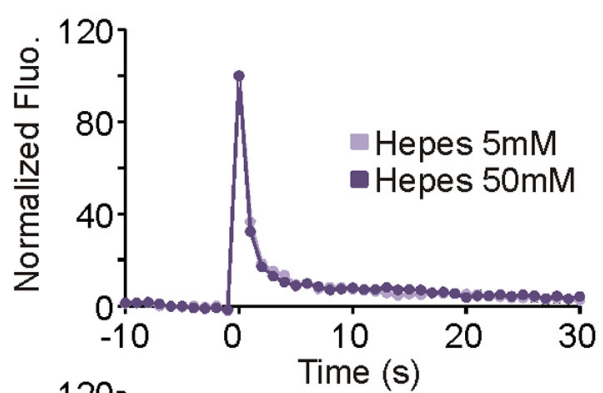

D

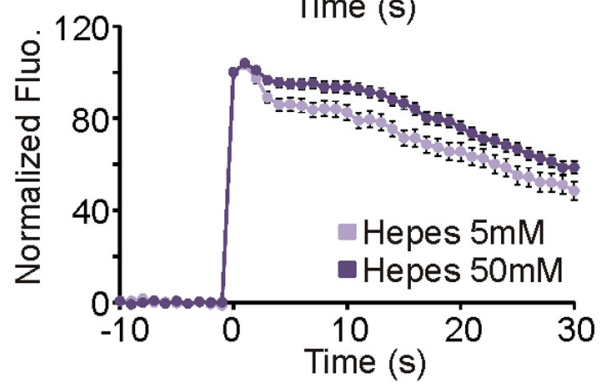

E
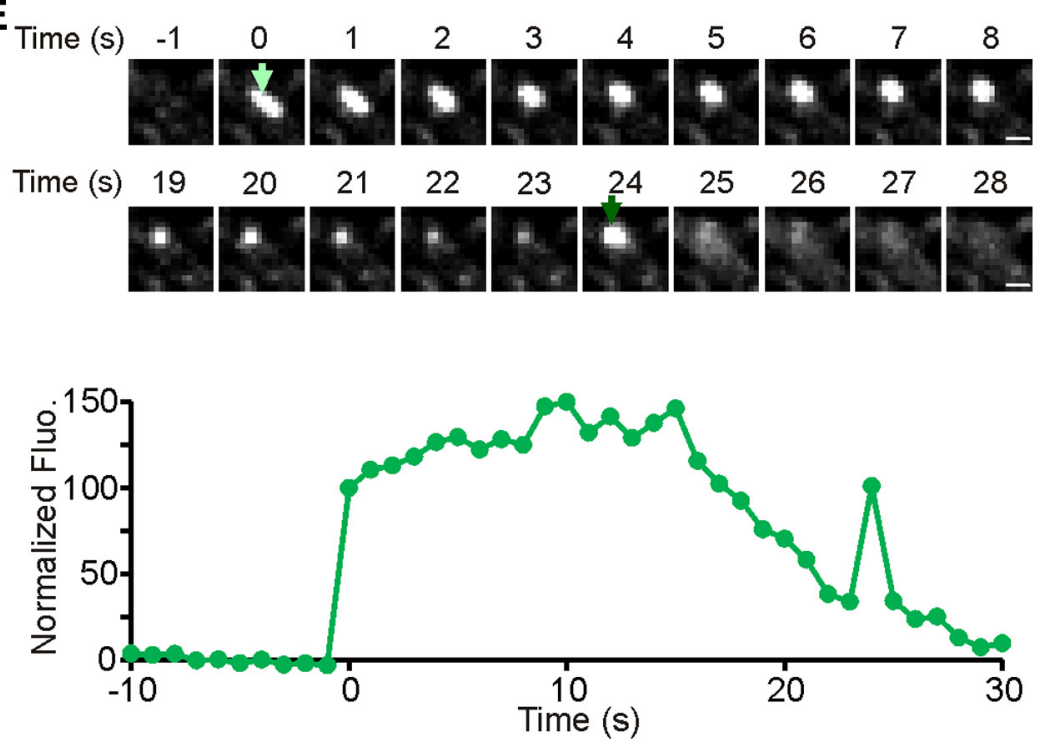

Figure 5. Behavior of REs after display exocytosis. $\boldsymbol{A}$, Time-lapse images of burst ( $\boldsymbol{a}$ ) and display $(\boldsymbol{b})$ events in neurons transfected with TfR-SEP and incubated with Tfn-A568 for 10 min at 50 $\mu \mathrm{g} / \mathrm{ml}$ before imaging. For the burst event, the point of Tfn enrichment (red arrow) decreases within seconds after exocytosis, whereas for the display exocytosis it remains stable. $\boldsymbol{B}$, Average normalized fluorescence for 1202 events recorded in 11 cells in the same conditions as in $D$ and separated into display (light green and red curves, 686 events) and burst (dark green and red curves, 516 events) events. Scale bars, $1 \mu \mathrm{m}$. C, $\boldsymbol{D}$, Average fluorescence of burst ( $\boldsymbol{C}$ ) and display (D) events recorded in solutions containing 5 or 50 mm HEPES (11 and 13 neurons, respectively). For comparison of burst and display event averages in 5 and 50 mм HEPES, we computed the sum of squared differences (SSDs) between curves in the two conditions and compared it with the same measure for events randomly assigned in either group (random permutation test). For display events, the SSD was more than two times higher than the $95 \%$ confidence interval for randomized data, whereas it was within the median SSD for randomized data for burst events. This shows that display events are significantly different in 5 and 50 mm $H E P E S$, whereas burst events are not. $\boldsymbol{E}$, Example of an organelle undergoing display ( $0 \mathrm{~s}$, light green arrow) and then burst exocytosis ( $24 \mathrm{~s}$, dark green arrow), also illustrating the variability in the kinetics of fluorescence decrease after display exocytosis.

blocking dynamin GTPase activity, dynasore has multiple effects (Park et al., 2013) so we measured the recruitment of dynamin2mCherry to display exocytosis events. This tagged protein is robustly recruited to sites of CME in non-neuronal (Taylor et al., 2011) and neuronal (our unpublished observations) cells. However, dynamin2-mCherry was not recruited to display or burst exocytosis (Fig. 7C). Therefore, we conclude that dynamins are not involved in fast internalization after RE exocytosis.

Actin filaments have also been implicated in many forms of membrane trafficking, including kiss-and-run exocytosis, for example of trans-Golgi carriers (Jaiswal et al., 2009). However, after treating neurons with latrunculin $\mathrm{A}(10 \mu \mathrm{M})$ for $20 \mathrm{~min}$, which depolymerizes actin filaments in cultured neurons (Zhou et al., 2001), we did not observe any alteration of the frequency of exocytosis events or the proportion of display events (Fig. 7D,E).
Recycled receptors exhibit multiple rounds of display exocytosis in the same REs

We wondered whether or not other recycled receptors were targeted to REs with the same exocytosis properties as TfR-SEP. Indeed, burst and display-like behaviors were reported for $\beta 2 \mathrm{AR}$ and GluA1 receptors (Yudowski et al., 2006, 2007), but the underlying mechanisms could be distinct from kiss-and-run. In cells transfected with SEP- $\beta 2 \mathrm{AR}$, the frequency of exocytic events was low in basal conditions (Fig. $8 C$ ). Application of the selective $\beta$-agonist isoproterenol $(10 \mu \mathrm{M})$ induced massive internalization and recycling of receptors. Effectively, during agonist application, the whole-cell fluorescence of SEP- $\beta 2$ AR decreased by $\sim 40 \%$ in $10 \mathrm{~min}$, consistent with internalization of receptors into acidic endosomes. Moreover, we followed the formation and behavior of endosomes by incubating transfected neurons with a 
A

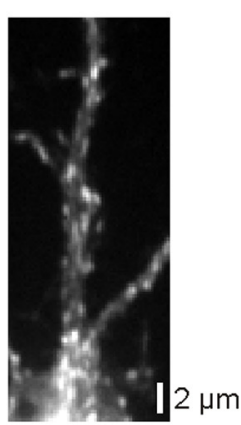

$B$

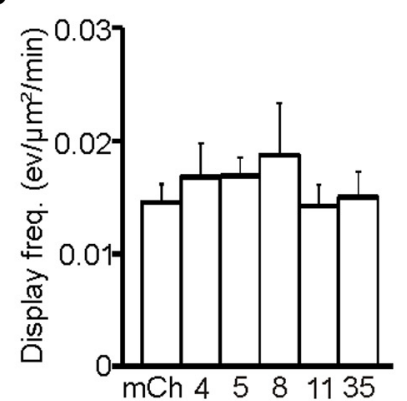

C

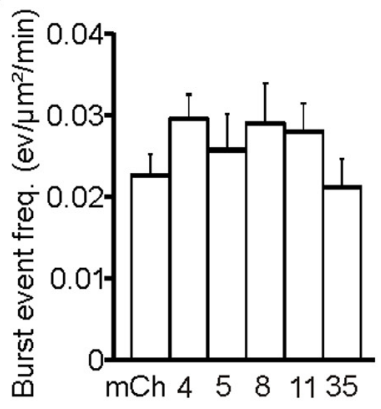

E

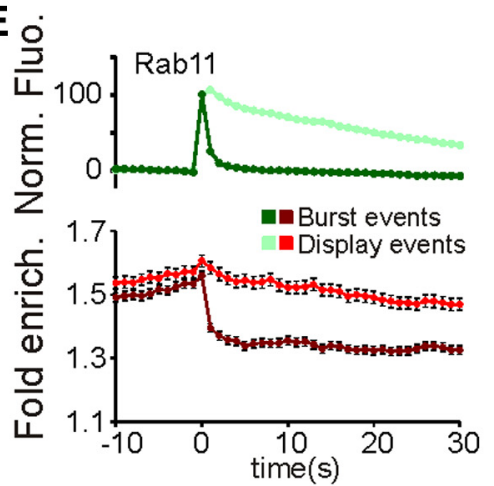

$\mathbf{F}$

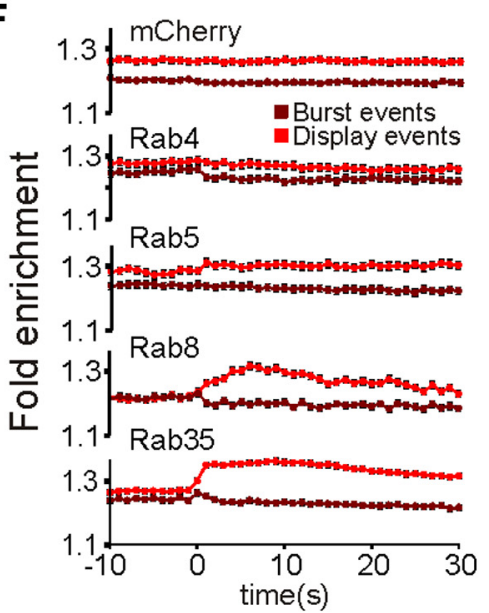

I

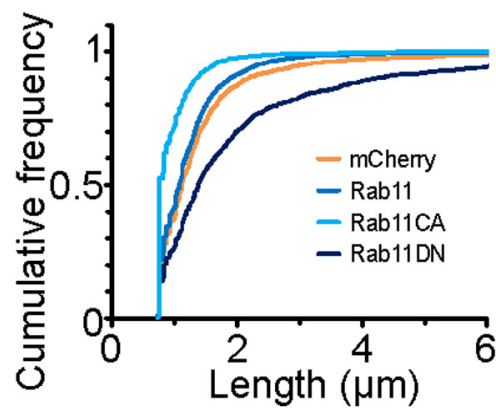

Figure 6. Involvement of Rab proteins during RE exocytosis. A, 14 DIV neuron cotransfected with TfR-SEP and Rab11-mCherry. Average (100 images from a $1 \mathrm{~Hz}$ time-lapse recording) of a portion of dendrite shows zones of Rab11-mCherry enrichment on a homogeneous background. $\boldsymbol{B}, \boldsymbol{C}$, Frequency of display $(\boldsymbol{B})$ and burst $(\boldsymbol{C})$ events in neurons transfected with Rab-mCherry proteins. There was no significant difference between cells transfected with $\mathrm{mCherry}$ and cells transfected with Rab-mCherry proteins $(9-12$ cells per condition). $\boldsymbol{D}$, Successive frames from $1 \mathrm{~Hz}$ time-lapse recordings in neurons transfected with TfR-SEP and Rab11-mCherry, showing the enrichment of Rab11-mCherry (red arrows) before exocytosis (green arrows). For the display event $(\boldsymbol{a})$, no change in Rab11-mCherry is observed, whereas for the burst event $(\boldsymbol{b})$, Rab11-mCherry is discarded in the frames after exocytosis. $\boldsymbol{E}$, Average normalized fluorescence for 2220 events recorded in 9 cells with Rab11-mCherry, separated into display (light green and red curves, 787 events) and burst (dark green and red curves, 1433 events). $\boldsymbol{F}$, Average normalized fluorescence for display events (red traces) and burst events in cells transfected with TfR-SEP and mCherry ( $n=1268$ and 856 events, respectively) or Rab4 ( $n=663$ and 1146$), \operatorname{Rab} 5$ ( $n=833$ and 988$)$, Rab8 ( $n=$ 682 and 933$)$, and Rab35 ( $n=1188 / 1327) \mathrm{m}$ Cherry fusion proteins. The average TfR-SEP traces have been omitted for clarity, but they are all very similar to the ones shown in $E$. G, Frequency of display events in neurons transfected with mutant Rab-mCherry proteins (11-14 cells per group). There was a significant decrease in cells transfected with Rab11CA-mCherry compared with $m$ Cherry alone $(* * * 0.001)$ but not with the other conditions. $\boldsymbol{H}$, Frequency of burst exocytosis events in the same sample as in $\boldsymbol{G}$. There was a significant decrease compared with control only in cells expressing Rab11DN-mCherry $\left({ }^{* *} p<0.01\right) . I$, Cumulative distribution of tubule length at the time of exocytosis showing a significant increase $\left(p<10^{-6}\right.$, Kolmogorov-Smirnov test) for neurons transfected with Rab11DN-mCherry versus $m$ Cherry and a significant decrease for neurons expressing Rab11CA-mCherry $\left(p<10^{-6}\right)$. There was also a slight decrease for Rab11-mCherry $(p=0.003)$.

monoclonal anti-GFP antibody labeled with the $\mathrm{pH}$-insensitive fluorophore Cy3 ( $\alpha \mathrm{GFP}-\mathrm{Cy} 3)$. Because receptors were internalized $\alpha \mathrm{GFP}-\mathrm{Cy} 3$, fluorescence remained stable but relocalized in clusters corresponding to endosomes (Fig. $8 A, B$ ). Most of these clusters remained relatively static, suggesting that recycling is essentially local (Choy et al., 2014). After agonist application, the frequency of exocytosis events increased 10 -fold but remained much lower than the frequency of TfR-SEP events (Fig. 8C), suggesting that $\mathrm{SEP}-\beta 2 \mathrm{AR}$ are localized to a subset of TfR-SEP- containing endosomes. Nevertheless, events recorded with SEP$\beta 2 \mathrm{AR}$ looked very similar to the ones recorded with TfR-SEP with a similar proportion of display events before and after application of isoproterenol (Fig. 8D). Exocytic events detected with SEP- $\beta 2 \mathrm{AR}$ occurred at endosomes marked with $\alpha \mathrm{GFP}-$ Cy3. For burst events, a decrease in both channels can be observed after exocytosis attributable to lateral diffusion of the receptor (Fig. $8 E$ ). Conversely, for display events, antibodies remained clustered even after SEP- $\beta 2 \mathrm{AR}$ essentially disappeared, 
A

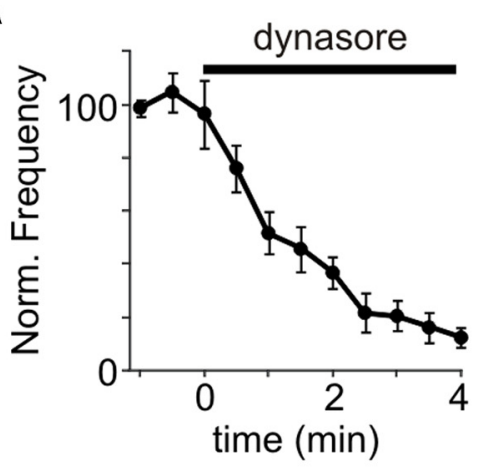

D

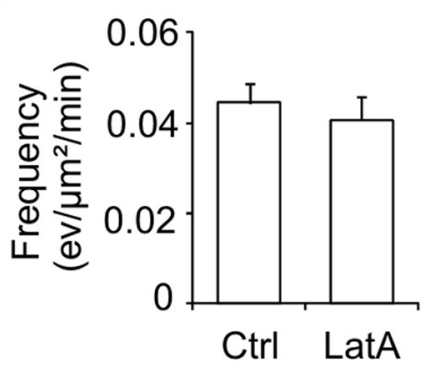

B

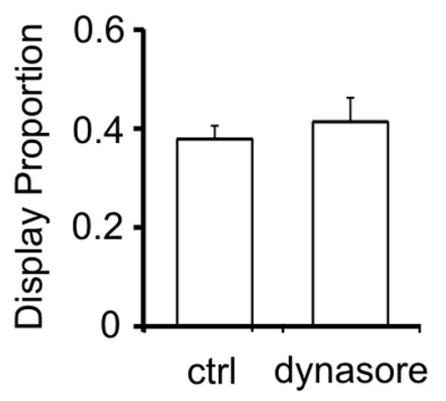

E

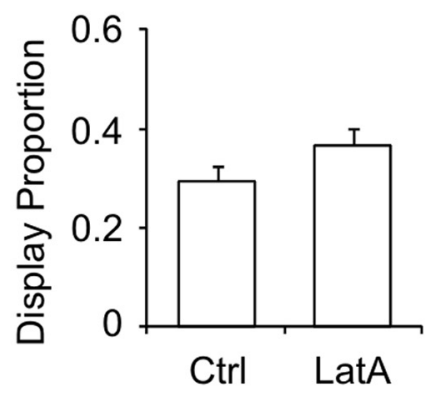

C

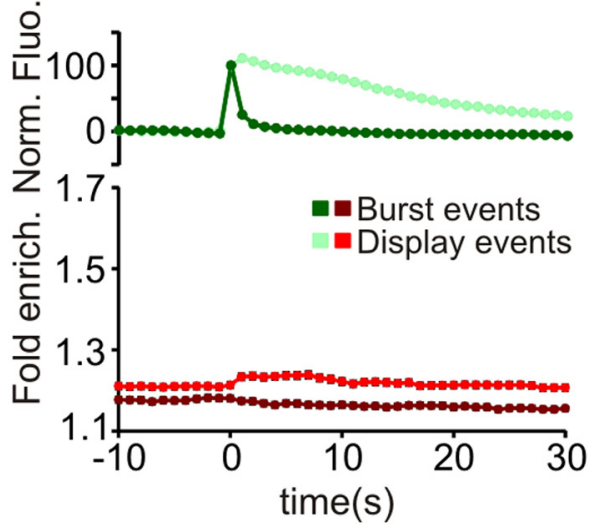

Figure 7. Dynamin and actin are not involved in display exocytosis. $\boldsymbol{A}$, Effect of dynasore $(80 \mu \mathrm{M})$ on display and burst event frequency ( $n=6$ cells). $\boldsymbol{B}$, Proportion of display events before and during dynasore application. C, Average normalized fluorescence sorted into display (light green and red curves) and burst (dark green and red curves) events for cells transfected with TfR-SEP and dynamin2-mCherry (1061 burst and 823 display events in 9 cells). $\boldsymbol{D}, \boldsymbol{E}$, Effect of latrunculin A (10 $\mu \mathrm{m}$, incubated for 20 min before recording) on the total frequency of events (D) and proportion of display events $(\boldsymbol{E})$. There was no significant difference in either parameter measured in 13 control (Ctrl) and 15 cells treated with latrunculin $A$ (LatA).

confirming that receptors did not slowly diffuse away after release but that the endosome acidified again (Fig. $8 F$ ). There were evidently multiple display events from the same endosome (Fig. $8 G$ ), separated by $10-200 \mathrm{~s}$ (Fig. $8 H$, median of $52 \mathrm{~s}$ ). This shows that REs undergoing display exocytosis provide none or a limited amount of receptors at the surface but can fuse multiple times with the plasma membrane. Conversely, burst events reflect the exocytosis mode, which allows recycling of the receptor back to the plasma membrane.

To explore further the link between exocytosis detected with the two different receptors, we cotransfected neurons with SEP$\beta 2 \mathrm{AR}$ and TfR fused to pHto (TfR-pHto), a $\mathrm{pH}$-sensitive red fluorescent protein ( $\mathrm{Li}$ and Tsien, 2012), and performed twocolor confocal imaging after isoproterenol application. In $35 \pm$ $6 \%$ of events detected with TfR-pHto, there was no detectable SEP- $\beta 2 A R$ signal (Fig. 8Ia). For the remaining events, SEP$\beta 2 \mathrm{AR}$ was also detected, and the two receptors reported the same type of events: (1) burst (Fig. 8Ib); or (2) display (Fig. 8Ic). This suggests that the type of exocytosis is determined for a given organelle, consistent with a mechanism involving the whole endosome. Finally, we applied the $\mathrm{ppH}$ protocol and observed for $\mathrm{SEP}-\beta 2 \mathrm{AR}$ the same type of profiles as for TfR-SEP, demonstrating internalization during display events (Fig. $8 \mathrm{~J}, \mathrm{~K}$ ). The distribution of opening times was similar, with a large proportion of fusion pore opening times smaller than $6 \mathrm{~s}$. Therefore, SEP$\beta 2 \mathrm{AR}$ retention after display exocytosis, like for TfR-SEP, is primarily attributable to fast receptor internalization. Finally, we recorded exocytosis events in neurons transfected with SEPGluA1, which show a large proportion of display events as well (Yudowski et al., 2007). Again, the ppH protocol revealed that SEP-GluA1 receptors are quickly internalized after display exocytosis, with a large majority of short opening times (Fig. $8 L, M$ ). However, for $20 \%$ of events, clusters of SEP-GluA1 were still visible but sensitive to low $\mathrm{pH}>14 \mathrm{~s}$ after exocytosis, suggesting that for these events receptors are not internalized but anchored. In conclusion, we show that, for three different recycled receptors, RE exocytosis is characterized in one-fourth of cases by kissand-run exocytosis or transient fusion pore opening.

\section{Discussion}

In this study, we have shown that hippocampal neurons exhibit a high rate of RE exocytosis that enables fast and local recycling of receptors. One-third of all exocytosis events, termed here display events, are characterized by opening and closure of a fusion pore (kiss-and-run) with a median opening time of $2.6 \mathrm{~s}$ and little exchange of receptors with the external medium. Consequently, single REs can support multiple rounds of exocytosis and allow neurons, through a choice between kiss-and-run and full fusion, to finely tune the amount of receptors delivered at the plasma membrane.

\section{High frequency of RE exocytosis in neuronal dendrites}

We have observed with TfR-SEP a much higher frequency of exocytosis events in neurons than in astrocytes or NIH 3T3 cells, from $7 \mathrm{DIV}$, when synapses just start to form and dendrite growth is still ongoing, to $21 \mathrm{DIV}$, when the neuronal network is considered mature (Kaech and Banker, 2006). The frequency of exocytosis events per surface area decreases approximately twofold between these two ages, but this change is attributable to the selective decrease of burst exocytosis events, whereas the frequency of display events remains constant throughout neuronal development. This likely reflects changes in dendrite growth, signaling, and metabolism in aged neurons.

We have shown with two-color imaging that REs containing SEP- $\beta 2$ AR represent a subset of endosomes marked with TfRpHto. The recycling of $\beta 2$ ARs in non-neuronal cells goes through specific REs that depend on actin filaments but that also contain TfRs (Puthenveedu et al., 2010). Therefore, REs containing 

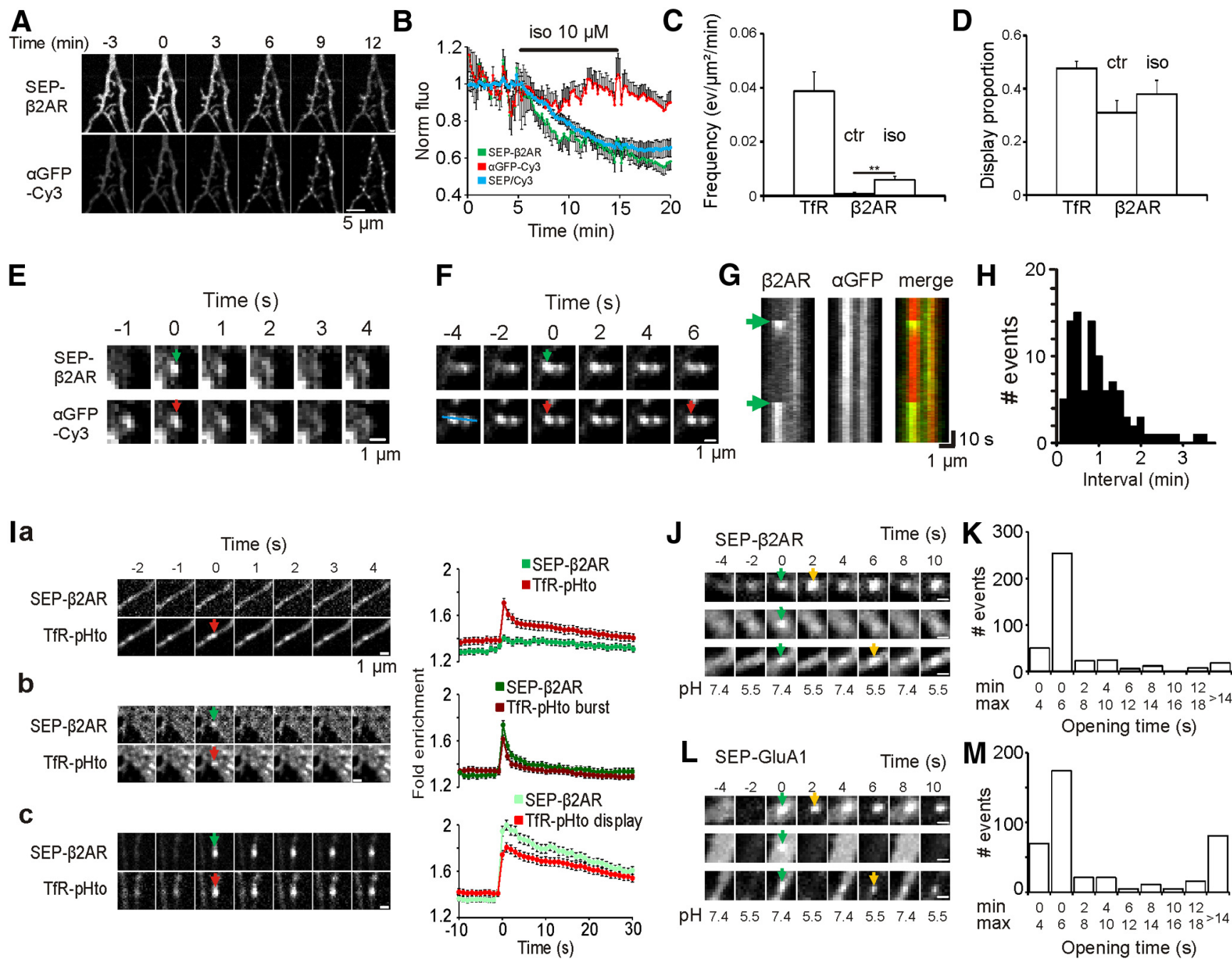

Figure 8. Multiple exocytosis events in single REs. A, Images of a neuron transfected with SEP- $\beta 2 A R$ and incubated with $\alpha$ GFP-Cy3. Isoproterenol, applied for 10 min at time 0 , induces within minutes the formation of $\alpha$ GFP-Cy3 clusters. B, Whole-cell fluorescence of SEP- $\beta 2 A R$ (green curve) and $\alpha$ GFP-Cy3 (red curve), normalized and averaged for six cells. The blue curve shows the ratio of SEP- $\beta 2 A R / \alpha$ GFP-Cy3 fluorescence. C, Frequency of exocytosis of TfR-SEP ( $n=9$ cells), $\beta 2 A R(n=10)$, and $\beta 2$ AR after stimulation with isoproterenol (Iso; $10 \mu \mathrm{m} ; n=10)$. Application of agonist increased significantly the frequency of $\beta 2$ AR exocytosis $(* * p<0.01)$. D, Proportion of display events from the same sample as in $\boldsymbol{C} . \boldsymbol{E}, \boldsymbol{F}$, Top, Images of burst $(\boldsymbol{E})$ and display $(\boldsymbol{F})$ events occurring at sites of $\alpha$ GFP-Cy3 enrichment (bottom). G, Kymographs made along the blue line in $\boldsymbol{F}$, starting $30 \mathrm{~s}$ after agonist washout. They show two successive exocytosis events detected in the left cluster of $\alpha$ GFP-Cy3, separated by $58 \mathrm{~s}$. $\boldsymbol{H}$, Histogram of the intervals between two exocytosis events from the same $\alpha$ GFP-Cy3 cluster (98 events in 7 cells). I, Left, Events detected in cells cotransfected with SEP- $\beta 2 A R$ and TfR-pHto, during isoproterenol washout. Right, Quantification of fluorescence normalized to whole-cell fluorescence for both red (TfR-pHto) and green (SEP- $\beta 2 A R$ ) channels for sorted populations. $\boldsymbol{a}$, Events detected with TfR-pHto but without detectable SEP- $\beta 2 A R$. Burst ( $\boldsymbol{b}$ ) and display (c) events are reported by both receptors simultaneously. $J$, Events recorded in neurons expressing SEP- $\beta 2 A R$ during ppH. Images at pH 5.5 are shown at $2 \times$ contrast for clarity. The three events shown represent the three main behaviors also seen with TfR-SEP (see Fig. 2B). Green arrows mark the time of exocytosis, and yellow arrows indicate the appearance of an acid-resistant cluster. $\boldsymbol{K}$, Histogram of estimated open times built as in Figure $3 C$ (396 events in 14 cells). L, Events recorded in neurons expressing SEP-GluA1 during ppH. Same as in J. M, Histogram of estimated open times built as in Figure 3 C (408 events in 11 cells).

$\beta 2 \mathrm{ARs}$ are likely to be a specific population of endosomes. Similarly, $40 \%$ of REs, marked by internalized transferrin, contain endogenous GluA1 (Ahmad et al., 2012) (Kennedy et al., 2010). Therefore, SEP-GluAl is probably in a subset of TfR-containing REs as well. However, the proportion of display and burst events recorded with these receptors was very similar, and simultaneous imaging of SEP- $\beta 2 \mathrm{AR}$ and TfR-pHto revealed the same type of exocytosis for both receptors in the same organelle. Interestingly, recycled $\mu$ opioid receptors undergo only burst events in striatal neurons, and addition of the sorting sequences of $\beta 2$ ARs promotes display events in these mutant receptors (Yu et al., 2010). This could reflect the specific sorting in a population of REs that does not make display exocytosis, further supporting a model of heterogeneity of the population of REs.
Display events reveal fast fusion pore opening and closing After display exocytosis, many clusters of receptors remain visible at an extracellular $\mathrm{pH}$ of 5.5 demonstrating a kiss-and-run mechanism for the vast majority ( $>85 \%$ ) of display events. Moreover, two-color experiments with internalized $\alpha \mathrm{GFP}-\mathrm{Cy} 3$ or TfnA568 clearly show that the decrease in fluorescence observed after display exocytosis is not attributable to slow or restricted diffusion of receptors in the plasma membrane as proposed previously (Yudowski et al., 2006; Yu et al., 2010) but to acidification of the closed RE. Therefore, the appearance of clustered receptors, such as SEP-GluA1 in dendritic shafts (Yudowski et al., 2007; Lin et al., 2009; Makino and Malinow, 2009; Araki et al., 2010), does not necessarily imply more receptors at the cell surface, and experiments using SEP fusion proteins in neurons should be in- 
terpreted with caution. However, in postsynaptic spines, SEPGluA1 is specifically retained, whereas TfR-mCherry diffuses away from the release site (Kennedy et al., 2010). In this case, the retention of AMPA receptors is likely attributable to binding to synaptic scaffold, not kiss-and-run. TfR-SEP exocytosis was almost never seen in spines in our recording conditions. It should be noted that display events and transient fusion pore opening were demonstrated on transfected cells only, and it cannot be strictly ruled out that this behavior may be a consequence of overexpressing tagged receptors. However, this was observed specifically in neurons, for three different types of receptors at all developmental ages and levels of overexpression, making this possibility unlikely. Our attempts to reveal this behavior with fluid phase markers, such as the $\mathrm{pH}$-sensitive pHrodo (Chen et al., 2013) were not successful, probably because of technical limitation of these probes to label, by fast pulse-chase experiments, small structures such as REs. Therefore, kiss-and-run exocytosis of REs in nontransfected neurons remains to be seen.

Multiple display exocytosis events occur in single REs with a median interval of $52 \mathrm{~s}$. Display events can be followed by a burst event, demonstrating that the two behaviors are not attributable to separated populations of REs but to different regulations of fusion mode. Moreover, the $\mathrm{pH}$ change protocols allowed us not only to measure fusion pore closure but also to detect exocytosis of non-acidic REs. Interestingly, the rate of RE acidification is highly variable after display exocytosis, and luminal $\mathrm{pH}$ can remain neutral for several tens of seconds. This parameter regulates ligand dissociation from its receptor, such as transferrin (DautryVarsat et al., 1983), and recycling is inhibited by blocking acidification with bafilomycin (Johnson et al., 1993). In neurons, endosomes containing neurotrophins or tetanus toxin have a neutral $\mathrm{pH}$ that regulates its retrograde transport in the axon (Bohnert and Schiavo, 2005). Therefore, $\mathrm{pH}$ could control the trafficking and release of cargo from REs in neuronal dendrites.

To our knowledge, this is the first time that kiss-and-run of REs is reported. Nevertheless, other organelles show kiss-andrun exocytosis. Secretory granules, such as dense-core granules in chromaffin cells and PC12 cells, experience closure of their fusion pore without full collapse into the plasma membrane and selective and partial release of soluble and membrane components, a process called kiss-and-run or cavicapture (Alés et al., 1999; Taraska et al., 2003; Perrais et al., 2004; Elhamdani et al., 2006; Chiang et al., 2014). Interestingly, the fusion pore open time of dense-core vesicles has been measured recently with optical techniques (Chiang et al., 2014), with values consistent with previous observations on transfected chromaffin cells (Perrais et al., 2004) and very similar to the ones we have obtained here for somatodendritic REs in neurons. The molecular mechanisms of kissand-run are far from resolved, but synaptotagmins could play a role (Wang et al., 2003; Segovia et al., 2010), as well as dynamin (Artalejo et al., 2002; Holroyd et al., 2002; Chiang et al., 2014). Kiss-and-run exocytosis of synaptic vesicles is still highly debated (Rizzoli and Jahn, 2007; Zhang et al., 2009), and its possible molecular mechanisms have remained elusive. Finally, trans-Golgi carriers can release part of their cargo in a way that is regulated by dynamin, clathrin, and actin (Jaiswal et al., 2009). However, for REs, display exocytosis events did not occur preferentially at clathrin-coated structures (Yudowski et al., 2006) and did not depend on dynamin or actin. We have shown that, among the classical Rab proteins linked to the endosomal system, only Rab11a-mCherry is enriched at REs until the moment of exocytosis, and that it is discarded immediately after burst exocytosis but is conserved after display exocytosis. Moreover, overexpres- sion of Rab11CA-mCherry or Rab11DN-mCherry selectively reduces the frequency of display or burst events, respectively. This is consistent with a role of Rab11 in controlling the recycling from REs. This could occur through the binding of the GTP bound form of Rab11 to effectors, such as Sec15, a subunit of the exocyst complex (Zhang et al., 2004). Finally, inhibition of burst exocytosis through Rab11DN overexpression is sufficient to inhibit recycling and has important consequences in neuronal function, such as inhibition of LTP and destabilization of dendritic spines (Park et al., 2004, 2006; Brown et al., 2007).

\section{Functional implications}

In this study, we demonstrate that REs undergoing display exocytosis provide none or a limited amount of receptors at the surface. On the contrary, burst events provide the final step in recycling of the receptor back to the plasma membrane. Switching from display to burst exocytosis would allow the timed delivery of receptors at specific sites. Conversely, receptor and cargo could be rapidly internalized after being accessible to extracellular ligand for a few seconds. Some receptors continue signaling after internalization (Sorkin and von Zastrow, 2009; Kotowski et al., 2011) and therefore can be quickly activated and maintain their signaling. Finally, long tubules, when connected to the plasma membrane, may change locally the electrical properties of dendrites. In conclusion, the high exocytosis rate of REs and kiss-and-run exocytosis add to the vast repertoire of neurons to modulate their signaling abilities and plasticity.

\section{Notes}

Supplemental material for this article is available at www.iins. u-bordeaux2.fr/component/content/article/487. This material has not been peer reviewed.

\section{References}

Ahmad M, Polepalli JS, Goswami D, Yang X, Kaeser-Woo YJ, Südhof TC, Malenka RC (2012) Postsynaptic complexin controls AMPA receptor exocytosis during LTP. Neuron 73:260-267. CrossRef Medline

Alés E, Tabares L, Poyato JM, Valero V, Lindau M, Alvarez de Toledo G (1999) High calcium concentrations shift the mode of exocytosis to the kiss-and-run mechanism. Nat Cell Biol 1:40-44. CrossRef Medline

Araki Y, Lin DT, Huganir RL (2010) Plasma membrane insertion of the AMPA receptor GluA2 subunit is regulated by NSF binding and Q/R editing of the ion pore. Proc Natl Acad Sci U S A 107:11080-11085. CrossRef Medline

Artalejo CR, Elhamdani A, Palfrey HC (2002) Sustained stimulation shifts the mechanism of endocytosis from dynamin-1-dependent rapid endocytosis to clathrin- and dynamin-2-mediated slow endocytosis in chromaffin cells. Proc Natl Acad Sci U S A 99:6358-6363. CrossRef Medline

Bohnert S, Schiavo G (2005) Tetanus toxin is transported in a novel neuronal compartment characterized by a specialized $\mathrm{pH}$ regulation. J Biol Chem 280:42336-42344. CrossRef Medline

Brown TC, Tran IC, Backos DS, Esteban JA (2005) NMDA receptordependent activation of the small GTPase Rab5 drives the removal of synaptic AMPA receptors during hippocampal LTD. Neuron 45:81-94. CrossRef Medline

Brown TC, Correia SS, Petrok CN, Esteban JA (2007) Functional compartmentalization of endosomal trafficking for the synaptic delivery of AMPA receptors during long-term potentiation. J Neurosci 27:13311-13315. CrossRef Medline

Chen M, Van Hook MJ, Zenisek D, Thoreson WB (2013) Properties of ribbon and non-ribbon release from rod photoreceptors revealed by visualizing individual synaptic vesicles. J Neurosci 33:2071-2086. CrossRef Medline

Chiang HC, Shin W, Zhao WD, Hamid E, Sheng J, Baydyuk M, Wen PJ, Jin A, Momboisse F, Wu LG (2014) Post-fusion structural changes and their roles in exocytosis and endocytosis of dense-core vesicles. Nat Commun 5:3356. CrossRef Medline

Choy RW, Park M, Temkin P, Herring BE, Marley A, Nicoll RA, von Zastrow 
M (2014) Retromer mediates a discrete route of local membrane delivery to dendrites. Neuron 82:55-62. CrossRef Medline

Dautry-Varsat A, Ciechanover A, Lodish HF (1983) pH and the recycling of transferrin during receptor-mediated endocytosis. Proc Natl Acad Sci U S A 80:2258-2262. CrossRef Medline

Elhamdani A, Azizi F, Artalejo CR (2006) Double patch clamp reveals that transient fusion (kiss-and-run) is a major mechanism of secretion in calf adrenal chromaffin cells: high calcium shifts the mechanism from kissand-run to complete fusion. J Neurosci 26:3030-3036. CrossRef Medline

Ferguson SM, De Camilli P (2012) Dynamin, a membrane-remodelling GTPase. Nat Rev Mol Cell Biol 13:75-88. CrossRef Medline

Gerges NZ, Backos DS, Esteban JA (2004) Local control of AMPA receptor trafficking at the postsynaptic terminal by a small GTPase of the Rab family. J Biol Chem 279:43870-43878. CrossRef Medline

Hirling H (2009) Endosomal trafficking of AMPA-type glutamate receptors. Neuroscience 158:36-44. CrossRef Medline

Holroyd P, Lang T, Wenzel D, De Camilli P, Jahn R (2002) Imaging direct, dynamin-dependent recapture of fusing secretory granules on plasma membrane lawns from PC12 cells. Proc Natl Acad Sci U S A 99:1680616811. CrossRef Medline

Jaiswal JK, Rivera VM, Simon SM (2009) Exocytosis of post-Golgi vesicles is regulated by components of the endocytic machinery. Cell 137:13081319. CrossRef Medline

Johnson LS, Dunn KW, Pytowski B, McGraw TE (1993) Endosome acidification and receptor trafficking: bafilomycin A1 slows receptor externalization by a mechanism involving the receptor's internalization motif. Mol Biol Cell 4:1251-1266. CrossRef Medline

Kaech S, Banker G (2006) Culturing hippocampal neurons. Nat Protoc 1:2406-2415. CrossRef Medline

Kennedy MJ, Ehlers MD (2011) Mechanisms and function of dendritic exocytosis. Neuron 69:856-875. CrossRef Medline

Kennedy MJ, Davison IG, Robinson CG, Ehlers MD (2010) Syntaxin-4 defines a domain for activity-dependent exocytosis in dendritic spines. Cell 141:524-535. CrossRef Medline

Kotowski SJ, Hopf FW, Seif T, Bonci A, von Zastrow M (2011) Endocytosis promotes rapid dopaminergic signaling. Neuron 71:278-290. CrossRef Medline

Kouranti I, Sachse M, Arouche N, Goud B, Echard A (2006) Rab35 regulates an endocytic recycling pathway essential for the terminal steps of cytokinesis. Curr Biol 16:1719-1725. CrossRef Medline

Li Y, Tsien RW (2012) pHTomato, a red, genetically encoded indicator that enables multiplex interrogation of synaptic activity. Nat Neurosci 15: 1047-1053. CrossRef Medline

Lin DT, Makino Y, Sharma K, Hayashi T, Neve R, Takamiya K, Huganir RL (2009) Regulation of AMPA receptor extrasynaptic insertion by $4.1 \mathrm{~N}$, phosphorylation and palmitoylation. Nat Neurosci 12:879-887. CrossRef Medline

Macia E, Ehrlich M, Massol R, Boucrot E, Brunner C, Kirchhausen T (2006) Dynasore, a cell-permeable inhibitor of dynamin. Dev Cell 10:839-850. CrossRef Medline

Makino H, Malinow R (2009) AMPA receptor incorporation into synapses during LTP: the role of lateral movement and exocytosis. Neuron 64:381390. CrossRef Medline

Merrifield CJ, Perrais D, Zenisek D (2005) Coupling between clathrincoated-pit invagination, cortactin recruitment, and membrane scission observed in live cells. Cell 121:593-606. CrossRef Medline

Park M, Penick EC, Edwards JG, Kauer JA, Ehlers MD (2004) Recycling endosomes supply AMPA receptors for LTP. Science 305:1972-1975. CrossRef Medline

Park M, Salgado JM, Ostroff L, Helton TD, Robinson CG, Harris KM, Ehlers MD (2006) Plasticity-induced growth of dendritic spines by exocytic trafficking from recycling endosomes. Neuron 52:817-830. CrossRef Medline

Park RJ, Shen H, Liu L, Liu X, Ferguson SM, De Camilli P (2013) Dynamin triple knockout cells reveal off target effects of commonly used dynamin inhibitors. J Cell Sci 126:5305-5312. CrossRef Medline

Patterson MA, Szatmari EM, Yasuda R (2010) AMPA receptors are exocytosed in stimulated spines and adjacent dendrites in a Ras-ERKdependent manner during long-term potentiation. Proc Natl Acad Sci U S A 107:15951-15956. CrossRef Medline
Perrais D, Kleppe IC, Taraska JW, Almers W (2004) Recapture after exocytosis causes differential retention of protein in granules of bovine chromaffin cells. J Physiol 560:413-428. CrossRef Medline

Petrini EM, Lu J, Cognet L, Lounis B, Ehlers MD, Choquet D (2009) Endocytic trafficking and recycling maintain a pool of mobile surface AMPA receptors required for synaptic potentiation. Neuron 63:92-105. CrossRef Medline

Puthenveedu MA, Lauffer B, Temkin P, Vistein R, Carlton P, Thorn K, Taunton J, Weiner OD, Parton RG, von Zastrow M (2010) Sequencedependent sorting of recycling proteins by actin-stabilized endosomal microdomains. Cell 143:761-773. CrossRef Medline

Rizzoli SO, Jahn R (2007) Kiss-and-run, collapse and 'readily retrievable' vesicles. Traffic 8:1137-1144. CrossRef Medline

Sankaranarayanan S, De Angelis D, Rothman JE, Ryan TA (2000) The use of pHluorins for optical measurements of presynaptic activity. Biophys J 79:2199-2208. CrossRef Medline

Segovia M, Alés E, Montes MA, Bonifas I, Jemal I, Lindau M, Maximov A, SüdhofTC, Alvarez de Toledo G (2010) Push-and-pull regulation of the fusion pore by synaptotagmin-7. Proc Natl Acad Sci U S A 107:1903219037. CrossRef Medline

Sorkin A, von Zastrow M (2009) Endocytosis and signalling: intertwining molecular networks. Nat Rev Mol Cell Biol 10:609-622. CrossRef Medline

Stenmark H (2009) Rab GTPases as coordinators of vesicle traffic. Nat Rev Mol Cell Biol 10:513-525. CrossRef Medline

Taraska JW, Perrais D, Ohara-Imaizumi M, Nagamatsu S, Almers W (2003) Secretory granules are recaptured largely intact after stimulated exocytosis in cultured endocrine cells. Proc Natl Acad Sci U S A 100:2070-2075. CrossRef Medline

Taylor MJ, Perrais D, Merrifield CJ (2011) A high precision survey of the molecular dynamics of mammalian clathrin-mediated endocytosis. PLoS Biol 9:e1000604. CrossRef Medline

Wang CT, Lu JC, Bai J, Chang PY, Martin TF, Chapman ER, Jackson MB (2003) Different domains of synaptotagmin control the choice between kiss-and-run and full fusion. Nature 424:943-947. CrossRef Medline

Wang Z, Edwards JG, Riley N, Provance DW Jr, Karcher R, Li XD, Davison IG, Ikebe M, Mercer JA, Kauer JA, Ehlers MD (2008) Myosin Vb mobilizes recycling endosomes and AMPA receptors for postsynaptic plasticity. Cell 135:535-548. CrossRef Medline

Watanabe S, Rost BR, Camacho-Pérez M, Davis MW, Söhl-Kielczynski B, Rosenmund C, Jorgensen EM (2013) Ultrafast endocytosis at mouse hippocampal synapses. Nature 504:242-247. CrossRef Medline

Xiong ZG, Zhu XM, Chu XP, Minami M, Hey J, Wei WL, MacDonald JF, Wemmie JA, Price MP, Welsh MJ, Simon RP (2004) Neuroprotection in ischemia: blocking calcium-permeable acid-sensing ion channels. Cell 118:687-698. CrossRef Medline

Yap CC, Winckler B (2012) Harnessing the power of the endosome to regulate neural development. Neuron 74:440-451. CrossRef Medline

Yu YJ, Dhavan R, Chevalier MW, Yudowski GA, von Zastrow M (2010) Rapid delivery of internalized signaling receptors to the somatodendritic surface by sequence-specific local insertion. J Neurosci 30:11703-11714. CrossRef Medline

Yudowski GA, Puthenveedu MA, von Zastrow M (2006) Distinct modes of regulated receptor insertion to the somatodendritic plasma membrane. Nat Neurosci 9:622-627. CrossRef Medline

Yudowski GA, Puthenveedu MA, Leonoudakis D, Panicker S, Thorn KS, Beattie EC, von Zastrow M (2007) Real-time imaging of discrete exocytic events mediating surface delivery of AMPA receptors. J Neurosci 27:11112-11121. CrossRef Medline

Zhang Q, Li Y, Tsien RW (2009) The dynamic control of kiss-and-run and vesicular reuse probed with single nanoparticles. Science 323:1448-1453. CrossRef Medline

Zhang XM, Ellis S, Sriratana A, Mitchell CA, Rowe T (2004) Sec15 is an effector for the Rab11 GTPase in mammalian cells. J Biol Chem 279: 43027-43034. CrossRef Medline

Zhou Q, Xiao M, Nicoll RA (2001) Contribution of cytoskeleton to the internalization of AMPA receptors. Proc Natl Acad Sci U S A 98:12611266. CrossRef Medline 